University of Nebraska - Lincoln

DigitalCommons@University of Nebraska - Lincoln

Biological Systems Engineering: Papers and

Publications

Biological Systems Engineering

2021

\title{
Assessing Different Plant-Centric Water Stress Metrics for Irrigation Efficacy Using Soil-Plant-Atmosphere-Continuum Simulation
}

Jingwen Zhang

Kaiyu Guan

Bin Peng

Ming Pan

Wang Zhou

See next page for additional authors

Follow this and additional works at: https://digitalcommons.unl.edu/biosysengfacpub

Part of the Bioresource and Agricultural Engineering Commons, Environmental Engineering Commons, and the Other Civil and Environmental Engineering Commons

This Article is brought to you for free and open access by the Biological Systems Engineering at DigitalCommons@University of Nebraska - Lincoln. It has been accepted for inclusion in Biological Systems Engineering: Papers and Publications by an authorized administrator of DigitalCommons@University of Nebraska Lincoln. 


\section{Authors}

Jingwen Zhang, Kaiyu Guan, Bin Peng, Ming Pan, Wang Zhou, Robert F. Grant, Trenton E. Franz, Daran Rudnick, Derek M. Heeren, Andrew Suyker, Yi Yang, and Genghong Wu 


\section{Water Resources Research}

\section{RESEARCH ARTICLE \\ 10.1029/2021WR030211 \\ Key Points: \\ - We conducted a systematic study to interpret six plant water stress (PWS) metrics and to assess their efficacy for guiding irrigation \\ - Canopy water potential and stomatal conductance are the most effective PWS metrics to characterize co- regulation of soil moisture and vapor pressure deficit \\ - The plant-centric irrigation schemes could save irrigation water use compared with soil-moisture-only metrics}

Supporting Information:

Supporting Information may be found in the online version of this article.

Correspondence to:

J. Zhang and K. Guan,

jingwenz@illinois.edu;

kaiyug@illinois.edu

Citation:

Zhang, J., Guan, K., Peng, B., Pan, M., Zhou, W., Grant, R. F., et al. (2021) Assessing different plant-centric water stress metrics for irrigation efficacy using soil-plant-atmosphere-continuum simulation. Water Resources Research, 57, e2021WR030211. https://doi. org/10.1029/2021WR030211

Received 15 APR 2021 Accepted 6 AUG 2021

\section{Assessing Different Plant-Centric Water Stress Metrics for Irrigation Efficacy Using Soil-Plant-Atmosphere- Continuum Simulation}

\author{
Jingwen Zhang ${ }^{1,2}$ (D), Kaiyu Guan ${ }^{1,2,3}$, Bin Peng ${ }^{1,2,3}$ (D), Ming Pan ${ }^{4,5}$, Wang Zhou ${ }^{1,2}$, \\ Robert F. Grant ${ }^{6}$ (D), Trenton E. Franz ${ }^{7}$ (D), Daran R. Rudnick ${ }^{8}$, Derek M. Heeren ${ }^{8}$, \\ Andrew Suyker ${ }^{5}$, Yi Yang ${ }^{1,2}$ iD, and Genghong $\mathrm{Wu}^{1,2}$ (D) \\ ${ }^{1}$ Agroecosystem Sustainability Center, Institute for Sustainability, Energy, and Environment, University of Illinois at \\ Urbana Champaign, Urbana, IL, USA, ${ }^{2}$ Department of Natural Resources and Environmental Sciences, College of \\ Agricultural, Consumer and Environmental Sciences, University of Illinois at Urbana Champaign, Urbana, IL, USA, \\ ${ }^{3}$ National Center for Supercomputing Applications, University of Illinois at Urbana Champaign, Urbana, IL, USA, \\ ${ }^{4}$ Department of Civil and Environmental Engineering, Princeton University, Princeton, NJ, USA, ${ }^{5}$ Center for Western \\ Weather and Water Extremes, Scripps Institution of Oceanography, University of California San Diego, La Jolla, \\ CA, USA, ${ }^{6}$ Department of Renewable Resources, University of Alberta, Edmonton, AB, Canada, ${ }^{7}$ School of Natural \\ Resources, University of Nebraska-Lincoln, Lincoln, NE, USA, ${ }^{8}$ Department of Biological Systems Engineering, \\ University of Nebraska-Lincoln, Lincoln, NE, USA
}

Abstract Understanding plant water stress (PWS) in the soil-plant-atmosphere-continuum (SPAC) that connects water supply from soil, water demand from atmosphere, and plant self-regulation is a prerequisite for efficient irrigation in response to water scarcity. Currently, PWS can be defined in various ways, for example, based on environmental factors and/or plant-centric metrics. The environment-based metrics usually do not take plants into consideration. Regarding the existing plant-centric metrics, their interconnections and abilities to capture the physical water constraints from both soil water supply and atmospheric water demand are still unclear. This research investigates the theoretical foundations behind different PWS metrics, and assesses their efficacy and potentials for irrigation scheduling. This study first investigated the interconnections among different PWS metrics and the co-regulation of soil moisture and vapor pressure deficit (VPD) on the plant-centric metrics through an advanced process-based model, ecosys. We then use ecosys to test different PWS metrics' performance in guiding irrigation in terms of water use, maize yield, and economic profits. The case study was conducted at sites across a dramatic rainfall gradient in Nebraska, the largest irrigation state in the United States Corn Belt. The ecosys simulation indicates that canopy water potential and stomatal conductance $\left(g_{s}\right)$ are the most effective plant-centric metrics in the SPAC system in indicating PWS. In addition, our findings show that using the plant-centric metrics-based irrigation schemes, which capture the co-regulation of soil moisture and VPD, can improve producers' economic profits through water savings.

\section{Introduction}

How to improve irrigation efficiency is a major challenge for both food production and water resource management in arid and semi-arid regions. Foundations to design efficient and effective irrigation lies in the understanding of plant water stress (PWS), that is, when and to what extent plant experiences stress related to water (Jones, 1990; Philip, 1966; Porporato et al., 2001). However, there is no universally adopted definition of PWS. Though various definitions of PWS based on soil moisture, evapotranspiration (ET), canopy temperature, stomatal conductance, and plant water potential exist, there is a lack of study on quantifying the mechanistic linkage among different definitions and how they perform in terms of guiding irrigation. The lack of the above knowledge hampers both water resource research and development of tools for irrigation management.

To better quantify PWS, we should explicitly consider the soil-plant-atmosphere-continuum (SPAC) that connects water supply from soil, water demand from atmosphere, and plant self-regulation (Passioura, 1982; Philip, 1966). Currently, PWS has been primarily defined using either environmental factors or plant-centric metrics (Figure 1; Zhang et al., 2021). Among the environment-based definitions, soil moisture is the (c) 2021. American Geophysical Union. All Rights Reserved. 


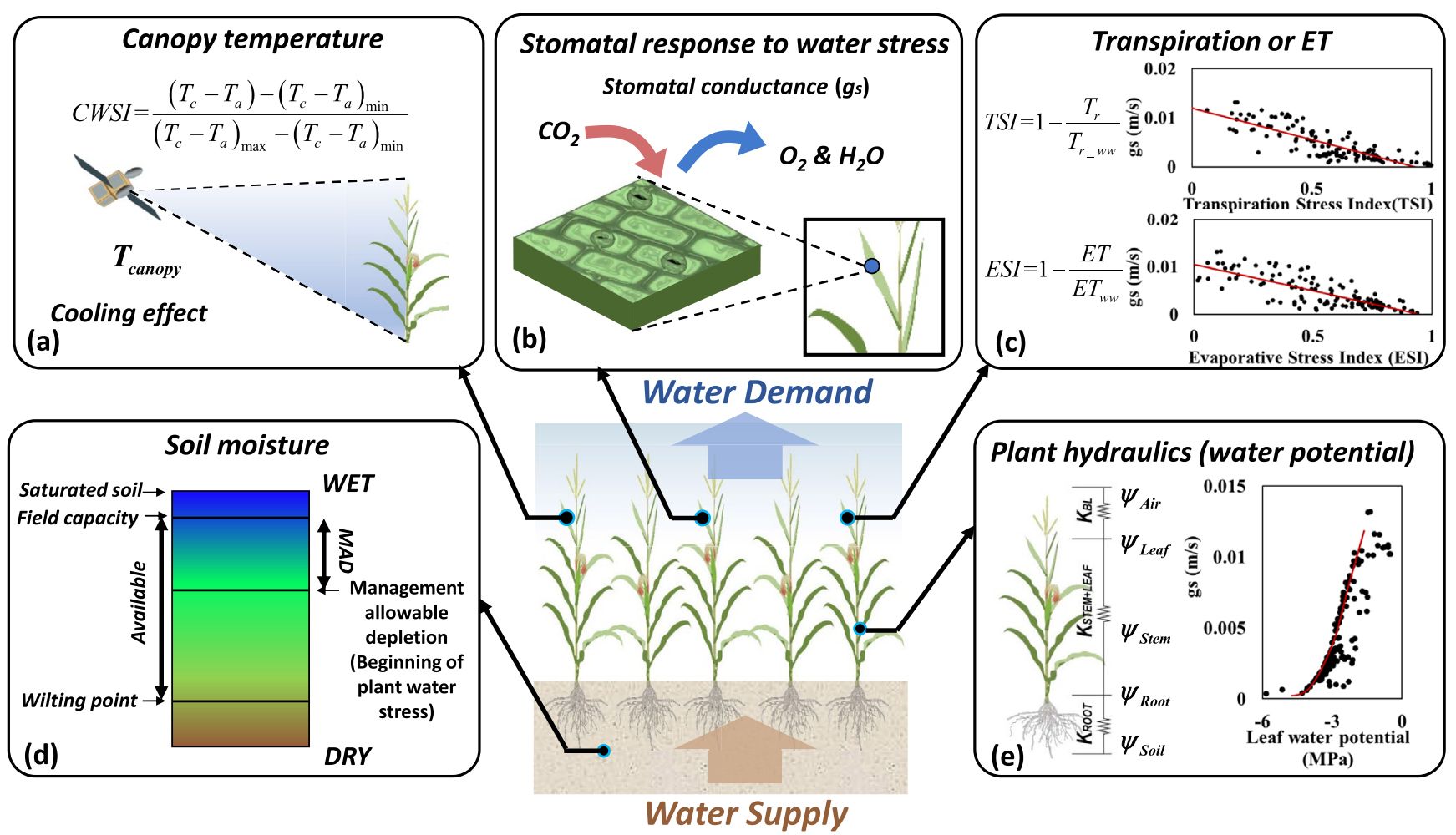

Figure 1. Six ways to measure/define PWS in SPAC (Zhang et al., 2021). (a) CWSI based on canopy temperature $\left(T_{\mathrm{c}}\right)$. $T_{\mathrm{a}}$ denotes air temperature. More details could be referred to Section 2 (Equation 2). (b) Stomatal conductance $\left(g_{\mathrm{s}}\right)$ considering stomatal response to water stress. (c) Transpiration stress index (TSI) and evaporative stress index (ESI) based on transpiration $\left(T_{\mathrm{r}}\right)$ or ET. $T_{\mathrm{r}_{-} \mathrm{ww}}$ and $\mathrm{ET}_{\mathrm{ww}}$ denote the transpiration and ET calculated under well-watered conditions without PWS. More details could be referred to Section 2 (Equations 5 and 6). (d) Soil moisture-based metric: management allowable depletion (MAD). (e) Leaf water potential based on plant hydraulics, including soil/root/stem/leaf water potential ( $\psi_{\text {Soil }}, \psi_{\text {Root }}, \psi_{\text {stem }}$, and $\left.\psi_{\text {Leaf }}\right)$ and atmospheric water potential ( $\psi$ Air).

most widely used metric as it characterizes the supply side of plant water use (Liu et al., 2020; Porporato et al., 2001); but vapor pressure deficit (VPD) plays an equal or sometimes more important role in regulating plant water use due to its control on stomatal conductance (Kimm, Guan, Gentine, et al., 2020; Lin et al., 2018; Lobell et al., 2014; López et al., 2021; Novick et al., 2016; Zhou et al., 2020). For the plant-centric ways to define PWS, several metrics have been suggested and used (Figure 1), including canopy temperature (Idso et al., 1981; Jackson et al., 1981), stomatal conductance (Ball et al., 1987; Leinonen et al., 2006; Medlyn et al., 2011), plant water potential (Herve, 2014), and ET (Anderson et al., 2007, 2016, 2018). Some literatures have investigated the linkage between several PWS metrics and physical water constraints from both soil water supply (i.e., soil moisture) and atmospheric water demand (i.e., VPD); they are based on field measurements (Grossiord et al., 2020; Jackson et al., 1981; López et al., 2021; Miner \& Bauerle, 2017) and/or process-based modeling (Anderson et al., 2007; Yang et al., 2019), while this analysis only covers one or two PWS metrics with different crop types or under different climate conditions. However, it is largely unclear on quantifying the mechanistic linkage among different plant-centric metrics, and what common and unique information they carry for capturing the physical water constraints of plants in the same SPAC system.

The direct implication of different PWS metrics is how they can be used for efficient irrigation, that is, irrigation timing and amount. Irrigation timing is usually indicated by the thresholds of different PWS metrics, while irrigation amount is determined by soil water balance. Currently, most irrigation schemes are soil moisture based, which only considers the stress from water supply while neglecting the stress from water demand (Gibson et al., 2017; Saseendran et al., 2008). The plant-centric metrics-based irrigation schemes can consider water stress arising from both water supply and demand aspects, such as the widely used crop water stress index (CWSI; DeJonge et al., 2015; Kullberg et al., 2017; Nandan et al., 2021) and plant water potential (Jones, 1990; Kumar et al., 2017; Nandan et al., 2021; Smart \& Barrs, 1973). Most plant-centric 
irrigation research focused on one or two PWS metrics using the field experiments (Cohen et al., 2005; Ihuoma \& Madramootoo, 2017; Kumar et al., 2017) and/or process-based modeling (Nandan et al., 2021) with different designed irrigation treatments, such as full/deficit irrigation. The discontinuous measurements of PWS metrics from field experiments were used to demonstrate their response to crop productivity. However, few researchers investigate different PWS metrics in the same SPAC framework, and pay attention to their optimal thresholds for efficient irrigation. In addition, current plant-centric irrigation schemes focus more on specialty crops with high-value, such as nuts (Carbonell-Barrachina et al., 2015), fruits (Bordonaba \& Terry, 2010; Moriana et al., 2012), vegetables (Çolak et al., 2015; Dukes et al., 2010; Kirnak et al., 2019; Sezen et al., 2014), while few for field crops, but field crops account for more than $71 \%$ of all planted acres of cropland across the United States (USDA, NASS, 2017). Different species have different responses to PWS with the species-specific plant traits (such as plant size) and physiological/biochemical adaptations due to different metabolism and biomass production in plant physiology (Enquist et al., 2007; Osakabe et al., 2014). Thus, a systematic way to understand the performance of different PWS metrics for irrigation guidance on field crops is needed for the development of better tools for irrigation management.

This study aims to quantify the mechanistic linkage among different PWS metrics and the physical water constraints in the same SPAC framework, and assesses their efficacy for guiding irrigation. We will answer two science questions: (a) To what extent do the PWS metrics interconnect and capture the stress from both soil water supply and atmospheric water demand? (b) What is the performance of PWS metrics in guiding irrigation? To answer these questions, we use the rigorously validated hydraulically driven ecosystem model (ecosys) to study different PWS metrics, and implement them as different irrigation schemes to assess their performances on water use, maize yield, and economic profits across 12 sites with a dramatic rainfall gradient in Nebraska during 2001-2019. It needs to be noted that this research is conducted based on the simulations from the ecosys model without field experiments. The ecosys model has been extensively validated its abilities to capture the sensitivities of carbon and water fluxes to soil moisture and VPD at both site and region scales in the United States Midwest (Grant et al., 1993, 2007; Grant \& Flanagan, 2007; Zhou et al., 2021). As it was almost impossible to conduct field experiments to test different PWS metrics-based irrigation schemes with different thresholds, we believe that this modeling approach, after going through rigorous model calibration and validation, could offer an effective way to make assessments of different PWS metrics for irrigation use.

\section{Plant Water Stress Metrics}

Five plant-centric and one environment-based metrics for PWS through the rigorously validated hydraulically driven ecosystem model (ecosys) are investigated in this study (Figure 1; Zhang et al., 2021).

1. Plant-centric: canopy water potential (CWP in Figures 1e and Equations 1 and 12). CWP is defined and calculated through canopy energy and water balance based on plant hydraulics, the fundamental theorem in SPAC, as the path of water flow follows the potential gradient (Anderegg, 2015). CWP decreases when soil and/or atmosphere becomes drier with lower soil water potential and/or higher VPD.

$$
\mathrm{CWP}=\min \left(\psi_{c, j}\right), j=1, \ldots, 24
$$

where $\psi_{\mathrm{c}, \mathrm{j}}$ is the CWP for each hour $j$ (MPa); CWP is the minimum of $\psi_{\mathrm{c}, \mathrm{j}}$ during each day (MPa).

2. Plant-centric: stomatal conductance ( $g_{s}$ in Figure $1 \mathrm{~b}$ and Equations 10 and 11). Stomatal conductance reflects the capacity of the uptake of $\left[\mathrm{CO}_{2}\right]$ for photosynthesis and water loss through transpiration with diurnal cycle (Ball et al., 1987; Medlyn et al., 2011). Due to the canopy structure, both leaf and canopy-level stomatal conductance $\left(g_{s}\right.$ and $G_{s}$ ) near midday (the averaged values in each day from 12:00 to 14:00) are widely used to describe the capacity of gas exchange (Kimm, Guan, Gentine, et al., 2020; Novick et al., 2016). As leaf area index (LAI), assumed to be constant through the peak growing season, is needed for the calculation of $G_{s}, g_{s}$ and $G_{s}$ are usually used for the whole growing season and the peak growing season, respectively, to avoid the impact of the change of LAI with crop growth. Observational evidence has demonstrated that stomatal conductance is regulated by both soil moisture and VPD (Grossiord et al., 2020; Kimm, Guan, Gentine, et al., 2020; Novick et al., 2016).

3. Plant-centric: CWSI (in Figure 1a and Equation 2). CWSI indicates PWS using the normalized difference between the canopy and air temperature. The upper and lower boundaries of temperature difference can 
be obtained by theoretical and empirical approaches. The theoretical approaches use energy balance to calculate the upper (Equation 3) and lower boundaries (Equation 4) with additional required measurements, such as aerodynamic resistance $\left(r_{\mathrm{a}}\right)$ and net radiation $\left(R_{\mathrm{n}}\right)$, assuming that the crop resistance is infinite for upper boundary (i.e., non-transpiring crop) and 0 as free water surface for lower boundary (i.e., well-watered crop), respectively (Hoffmann et al., 2016; Jackson et al., 1981, 1988). For the empirical approaches, the upper and lower boundaries of canopy-air temperature difference are estimated as linear functions of VPD based on field experiments (Idso et al., 1982), while these linear functions are crop, growth-stage, and climate-specific. CWSI measures PWS through lower cooling effects due to the decreased transpiration, with 0 and 1 representing no water stress and maximum water stress, respectively.

$$
\begin{gathered}
\text { CWSI }=\frac{\left(T_{c}-T_{a}\right)-\left(T_{c}-T_{a}\right)_{\min }}{\left(T_{c}-T_{a}\right)_{\max }-\left(T_{c}-T_{a}\right)_{\min }}, \\
\left(T_{c}-T_{a}\right)_{\max }=\frac{r_{a}\left(R_{n}-G\right)}{\rho c_{p}}, \\
\left(T_{c}-T_{a}\right)_{\min }=\frac{r_{a}\left(R_{n}-G\right)}{\rho c_{p}} \times \frac{\gamma}{\gamma+\Delta}-\frac{\left(\boldsymbol{e}_{a}^{*}-\boldsymbol{e}_{a}\right)}{\gamma+\Delta},
\end{gathered}
$$

where $T_{\mathrm{c}}$ and $T_{\mathrm{a}}$ are canopy and air temperatures $\left({ }^{\circ} \mathrm{C}\right)$, respectively; $r_{\mathrm{a}}$ is aerodynamic resistance $\left(\mathrm{s} \mathrm{m}^{-1}\right)$; $R_{\mathrm{n}}$ is the net radiation $\left(\mathrm{W} \mathrm{m}^{-2}\right) ; G$ is the soil heat flux $\left(\mathrm{W} \mathrm{m}^{-2}\right) ; \rho$ is the density of air $\left(\mathrm{kg} \mathrm{m}^{-3}\right) ; c_{\mathrm{p}}$ is the heat capacity of air $\left(\mathrm{J} \mathrm{kg}^{-1}{ }^{\circ} \mathrm{C}^{-1}\right) ; \gamma$ is the psychrometric constant $\left(\mathrm{Pa}^{\circ} \mathrm{C}^{-1}\right) ; \Delta$ is the slope of the saturated vapor pressure-temperature relationship calculated at the average of canopy and air temperature $\left(\mathrm{Pa}{ }^{\circ} \mathrm{C}^{-1}\right) ; e^{*}$ is the saturated vapor pressure at $T_{\mathrm{a}}(\mathrm{Pa})$; and $e_{\mathrm{a}}$ is the vapor pressure of the air $(\mathrm{Pa})$.

4. Plant-centric: ESI (in Figure 1c and Equation 5). ESI, proposed by Anderson et al. (2011), quantifies the anomalies in the ratio of actual to potential ET (PET) to represent the spatial and temporal variation of meteorological drought (González-Dugo et al., 2021). As the ratio of ET/PET has the seasonal pattern due to LAI impacts rather than PWS (Jiang et al., 2020; Zhang et al., 2021), that is, ET/PET is larger during the peak growing season, we suggest using ET under well-watered conditions $\left(\mathrm{ET}_{\mathrm{ww}}\right)$ to replace PET in order to calculate ESI in Equation 5

$$
\mathrm{ESI}=1-\frac{\mathrm{ET}}{\mathrm{ET}_{w w}} .
$$

5. Plant-centric: TSI (in Figure 1c and Equation 6). Transpiration ( $\left.T_{\mathrm{r}}\right)$, limited by both soil water deficit and atmospheric dryness, can be achieved as the minimum of atmospheric water demand and soil water supply (Sinclair, 2012, 2018; Sinclair et al., 1984). Atmospheric water demand can be estimated as transpiration under well-watered conditions $\left(T_{\mathrm{r}_{-} w \mathrm{w}}\right)$, while soil water supply is estimated using root water uptake given limited soil moisture. Thus, we define TSI as the ratio of actual $T_{\mathrm{r}}$ (with PWS) and $T_{\mathrm{r}_{-} w w}$ (without PWS) to indicate PWS.

$$
\mathrm{TSI}=1-\frac{T_{r}}{T_{r_{-} w w}}
$$

6. Soil moisture-based: $M A D$ (in Figure 1d and Equation 7). MAD, the percentage of the available water in the root-zone varying with dynamic root-growth, is the most widely used metric to measure PWS for irrigation (Lehmann et al., 2013; Panda et al., 2004). The weighted average of soil moisture in multiple layers in the root-zone is calculated as MAD (Equation 8), with 0 and 1 representing field capacity and wilting point, respectively.

$$
\mathrm{MAD}=\frac{\boldsymbol{\theta}_{f c}-\boldsymbol{\theta}_{R Z}}{\boldsymbol{\theta}_{f c}-\boldsymbol{\theta}_{w p}}
$$




$$
\boldsymbol{\theta}_{R Z}=\frac{\sum_{n=1}^{N} \boldsymbol{\theta}_{n} \times d_{n}}{\sum_{n=1}^{N} d_{n}}
$$

where $\theta_{\mathrm{fc}}$ and $\theta_{\mathrm{wp}}$ are the field capacity and wilting point in the root-zone, respectively; $\theta_{\mathrm{RZ}}$ is the soil moisture in the root-zone; $\theta_{n}$ is the soil moisture in the soil layer $n ; d_{n}$ is the depth of the soil layer $n$; and $N$ is the total number of soil layers in the root-zone.

\section{Materials and Methods}

\subsection{Study Area}

We carried out a case study in Nebraska, the largest irrigation state in the United States Corn Belt (Figure 2a). The 12 irrigated sites across Nebraska with a dramatic rainfall gradient (from $900 \mathrm{~mm}$ in the east to $350 \mathrm{~mm}$ in the west) were selected to study different PWS metrics and to assess their efficacy and potentials for irrigation under different climate conditions (Figure $2 b$ ).

\subsection{Process-Based Model: Ecosys}

We used an advanced process-based ecosystem model (ecosys) to simulate the water, carbon, energy, and nutrient cycles based on biophysical and biochemical mechanisms (Grant, 1995; Grant et al., 1993;Grant, Jarvis, et al.,2001), which has been extensively validated in various agricultural ecosystems (Grant, 1995; Grant, Dyck, \& Puurveen, 2020; Grant \& Flanagan, 2007; Grant, Jarvis, et al., 2001; Grant et al., 1993, 199 9, 2007, 2011), including soil moisture (Grant, 1995; Grant \& Flanagan, 2007; Grant et al., 1993, 2007), ET (i.e., latent heat flux; Grant, 1995; Grant \& Flanagan, 2007; Grant, Jarvis, et al., 2001; Grant et al., 1993, 199 9, 2004, 2007), canopy temperature (Grant et al., 1999, 2011), leaf water potential (Grant et al., 1999, 2004), leaf stomatal conductance (Grant et al., 1999; Grant, Jarvis, et al., 2001). Ecosys can simulate all major agricultural management practices, such as tillage (Grant, 1997), crop rotation (Grant, 1997; Grant, Dyck, \& Puurveen, 2020), fertilizer (Grant, Juma, et al., 2001), and irrigation (Grant et al., 2004, 2007).

\subsubsection{Soil-Plant Water Relations in Ecosys}

The ecosys model uses a multi-layered soil-root-canopy system to get hourly two-stage convergence solutions for crop carbon assimilation, water uptake, and energy fluxes (Figure 3; Dimitrov et al., 2011; Grant, 1995, 2001; Grant et al., 1993, 1999, 2007; Grant, Jarvis, et al., 2001; Grant, Lin, \& Hernandez-Ramirez, 2020). Canopy temperature is calculated first through a solution of the canopy energy balance (Equation 9). Then ecosys calculates CWP $\left(\psi_{\mathrm{c}}\right)$ at which canopy transpiration/evaporation $\left(E_{\mathrm{c}}\right)$ based on canopy energy balance (left term in Equation 12) equilibrates with root/mycorrhizal water uptake from multiple soil layers and capacitance (right term in Equation 12). $E_{\mathrm{c}}$ is controlled by aerodynamic resistance (Grant, 1995; Grant et al., 1993; Van Bavel \& Hillel, 1976) and canopy stomatal resistance $\left(r_{\mathrm{c}}\right)$, which is jointly controlled by the balance between canopy photosynthesis (leaf level driven by rates of carboxylation vs. diffusion, Equation 10) and canopy turgor potential $\left(\psi_{t}\right.$, canopy level constrained by water status, Equation 11) dynamics (Grant \& Flanagan, 2007; Grant et al., 2007). Root water uptake is the total water uptake from different soil layers in the root-zone by root surfaces, which equilibrates the water transport from soil to roots and from roots to canopy. This is controlled by radial resistances from soil to root surfaces $\left(r_{\mathrm{s}}\right)$, radial resistances from those surfaces to root axes $\left(r_{\mathrm{r}}\right)$, and axial resistances from root axes to canopy ( $r_{\mathrm{a}}$; Equation 12). When there is a soil water deficit in SPAC, that is, decreasing soil water content and hence soil water potential $\left(\psi_{\mathrm{s}}\right)$ in each soil layer, the hydraulic resistances $\left(r_{\mathrm{s}}, r_{\mathrm{r}}\right.$, and $\left.r_{\mathrm{a}}\right)$ all increase, which results in lower root water uptake, forcing lower root water potential $\left(\psi_{\mathrm{r}}\right)$ and $\psi_{\mathrm{c}}$, thus lowering $\psi_{\mathrm{t}}$ and thereby a decline of stomatal conductance $\left(g_{\mathrm{s}}=1 / r_{\mathrm{c}}\right)$. When there is atmospheric dryness in SPAC, that is, high VPD, transpiration increases at first, forcing lower $\psi_{\mathrm{s}}$ and $\psi_{\mathrm{c}}$, thus leading to the same consequence of decreased $\psi_{\mathrm{t}}$ and $g_{\mathrm{s}}$, followed by lower transpiration ultimately.

$$
R_{n}=L E+H+G
$$




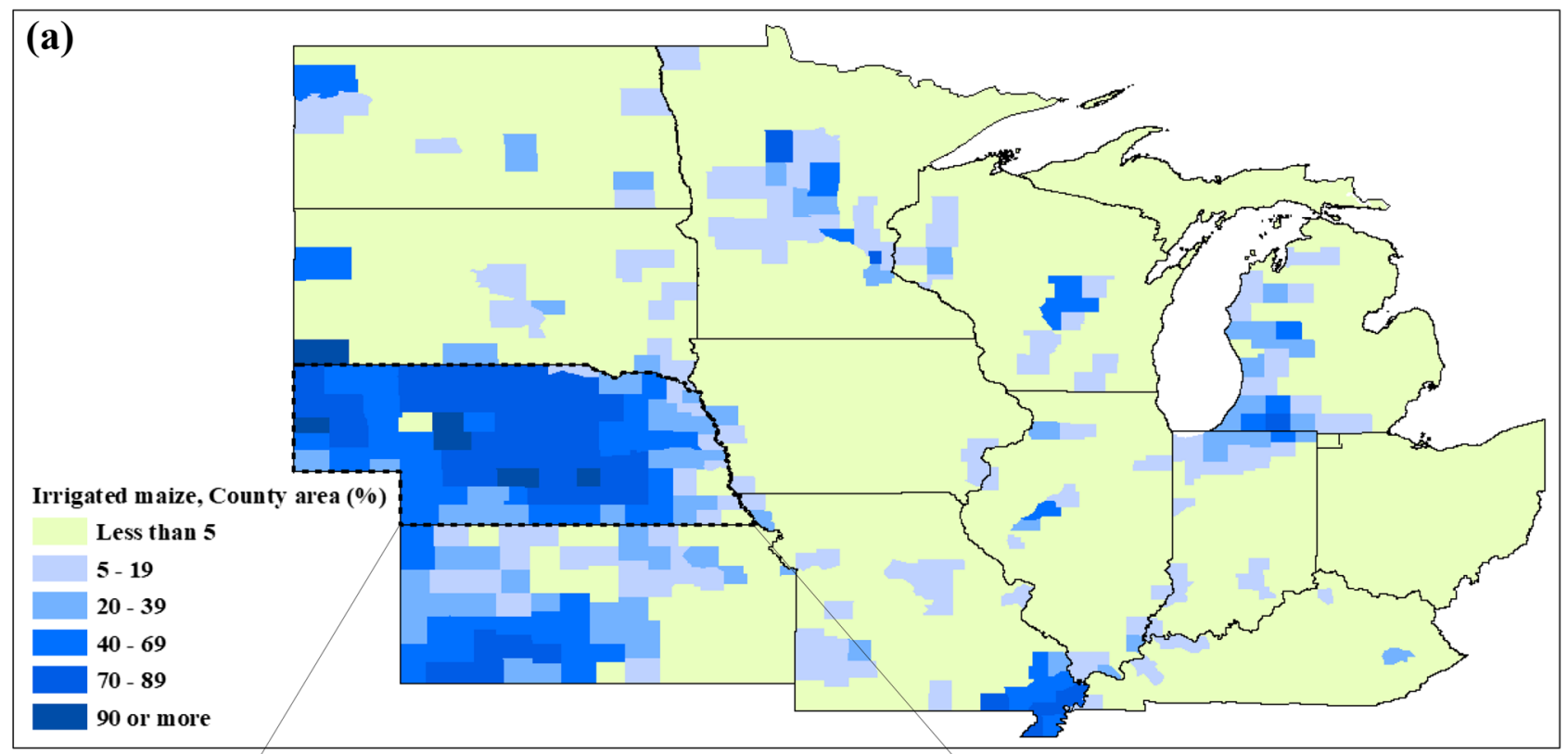

(b)

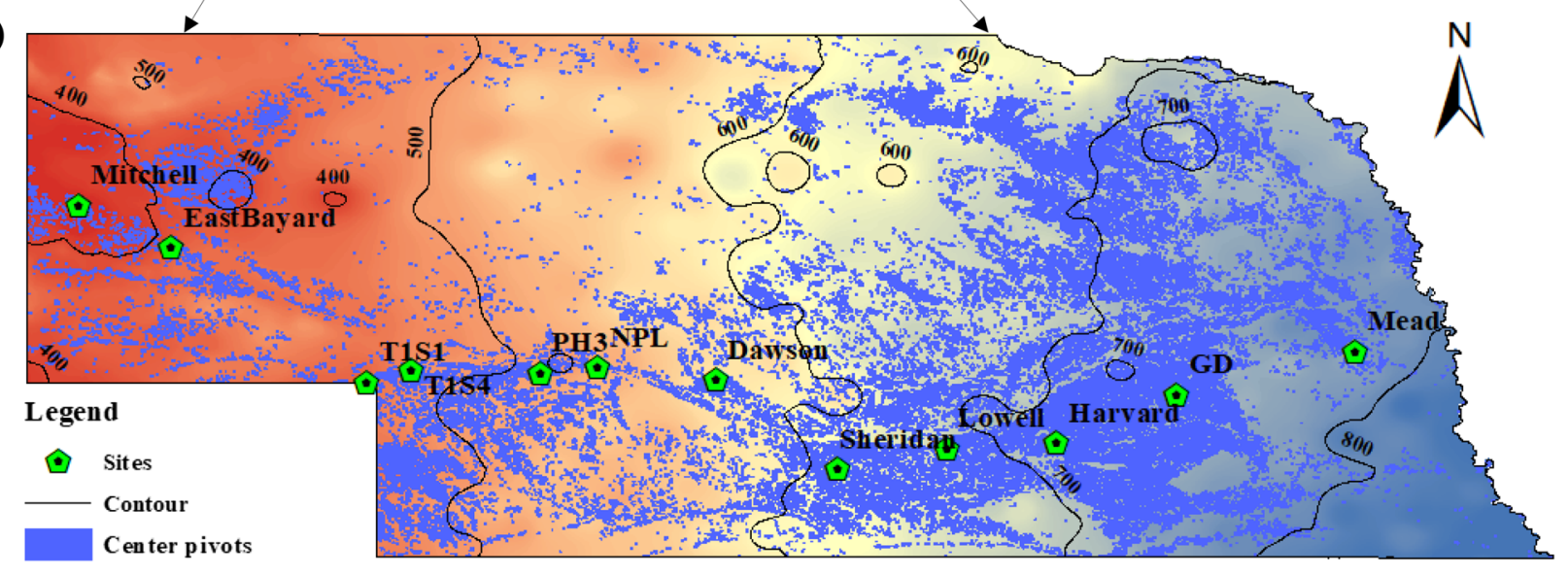

Annual Precipitation (mm)
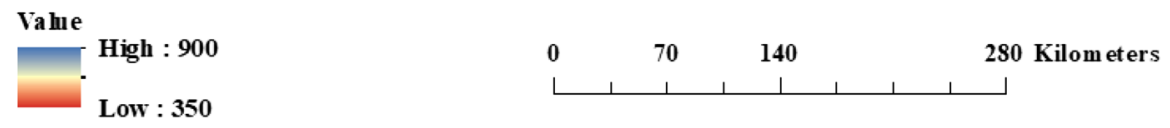

Figure 2. (a) The percentage of irrigated maize in the United States Corn Belt based on USDA, NASS, 2017 Census of Agriculture (https://www.nass.usda.gov). (b) Location of 12 sites with a dramatic rainfall gradient across Nebraska with spatial distribution of center pivot irrigation systems (http://snr.unl.edu/data/ geographygis/water.aspx).

$$
\begin{gathered}
r_{c(\min )}=\frac{\left(C_{b}-C_{i}^{\prime}\right)}{\left(1.56 V_{c}^{\prime}\right)}, \\
r_{c}=r_{c(\min )}+\left(r_{c(\max )}-r_{c(\min )}\right) e^{-5.0 \psi t}, \\
\psi_{t}=\psi_{c}-\psi_{\pi},
\end{gathered}
$$




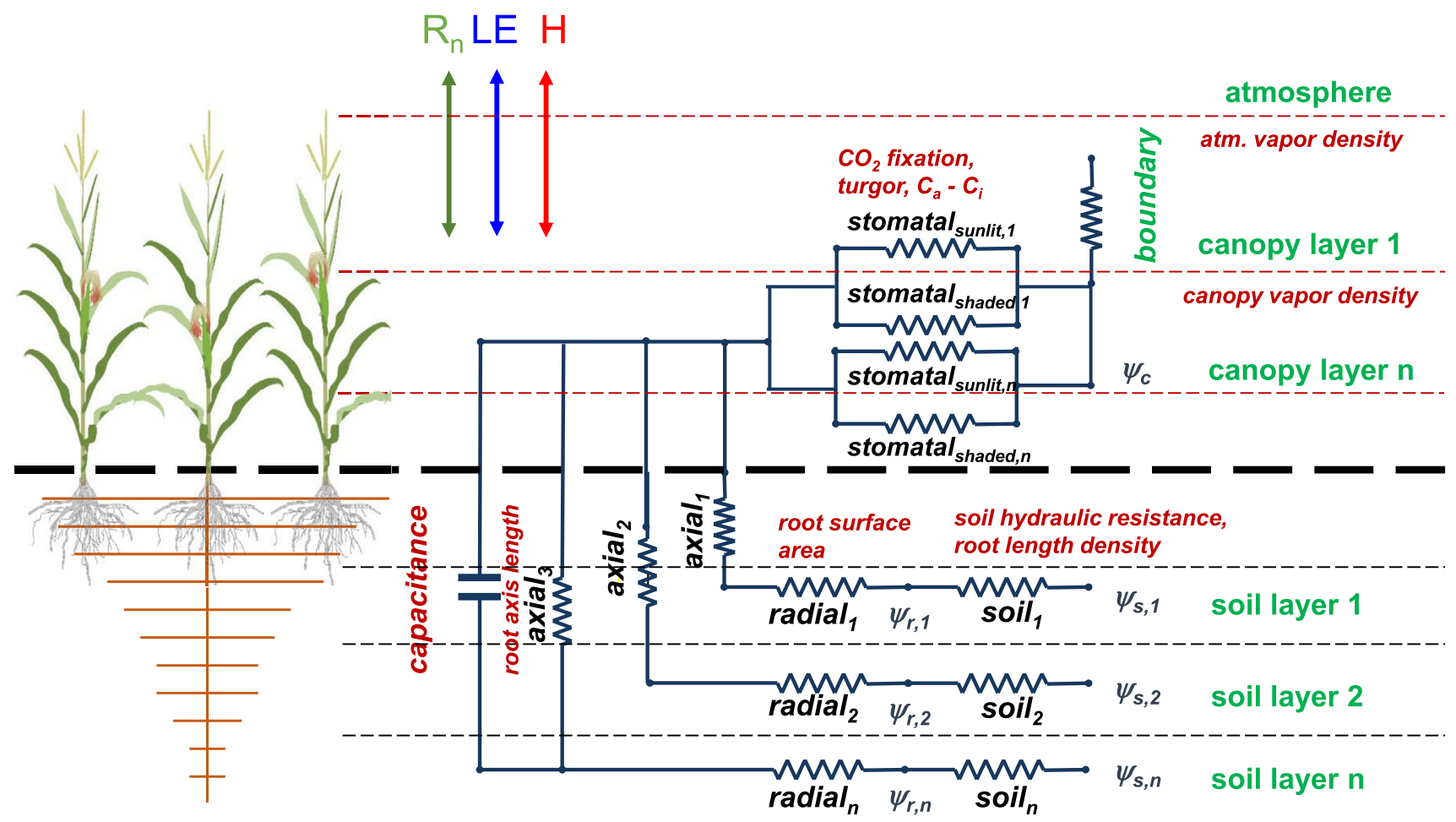

Figure 3. Conceptual diagram for the mechanism of plant water relations in ecosys.

$$
\left(e_{a}-e_{c}\right) /\left(r_{a}+r_{c}\right)=\frac{\sum_{n}\left(\psi_{c}-\psi_{s, n}\right)}{\left(r_{s, n}+r_{r, n}+r_{a, n}\right)}+X_{c} \delta \psi_{c} / \delta t,
$$

where $\boldsymbol{R}_{\mathrm{n}}$ is net radiation; $\boldsymbol{L} \boldsymbol{E}$ is latent heat flux; $\boldsymbol{H}$ is sensible heat flux; $\boldsymbol{G}$ is change in heat storage; $r_{\mathrm{c}(\min )}$ is the minimum $r_{\mathrm{c}}$ at $\psi_{\mathrm{c}}=0 \mathrm{MPa} ; r_{\mathrm{c}(\max )}$ is canopy cuticular resistance to vapor flux; $C_{\mathrm{b}}$ is the $\mathrm{CO}_{2}$ concentration in canopy air; $C_{\mathrm{i}}^{\prime}$ is the $\mathrm{CO}_{2}$ concentration in canopy leaves at $\psi_{\mathrm{c}}=0 \mathrm{MPa} ; V_{\mathrm{c}}^{\prime}$ is the potential canopy $\mathrm{CO}_{2}$ fixation rate at $\psi_{\mathrm{c}}=0 \mathrm{MPa} ; \psi_{\pi}$ is canopy osmotic potential; $e_{\mathrm{a}}$ is atmospheric vapor density at air temperature $\left(T_{\mathrm{a}}\right)$ and ambient humidity; $e_{\mathrm{c}}$ is canopy vapor density at canopy temperature $\left(T_{\mathrm{c}}\right)$ and $\psi_{c} ; n$ is soil layer; and $X_{c}$ is canopy capacitance.

\subsubsection{Photosynthesis in Ecosys}

Photosynthesis at the leaf-level is calculated using the Farquhar model for C3 plants and the Farquhar model plus a mesophyll-bundle sheath carbon exchange model for $\mathrm{C} 4$ plants with specific azimuth, leaf inclination, light exposure (i.e., sunlit and shaded leaves), and canopy height. Canopy photosynthesis is the sum of the photosynthesis of all individual leaves. The carbohydrate product is then allocated for maintenance respiration $\left(R_{\mathrm{m}}\right)$ in both shoot and root, growth respiration $\left(R_{\mathrm{g}}\right)$, and dry mass $(\mathrm{DM})$ formation. The phenologically driven plant carbon allocation ratio of shoot to root is impacted by the number of phyllochron intervals and the water and nutrient status of the plant. DM of shoots is partitioned to seven organs (leaf, sheath, stalk, soluble reserves, husk, cob, and grain) with dynamic partitioning ratios varying with growing stages. Seed number and kernel mass are set during pre- and post-anthesis growth stages to determine the yield upon harvest (Grant et al., 2011). More details about the biophysical and biochemical processes in ecosys can be found in the supplement of Grant, Lin, and Hernandez-Ramirez (2020).

\subsubsection{Model Calibration}

The ecosys model with maize cropping systems was rigorously calibrated and validated at three AmeriFlux sites (US-Ne1, US-Ne2, and US-Ne3, https://ameriflux.lbl.gov/) and 12 sites with a dramatic rainfall gradient across Nebraska (Figure 2). Three AmeriFlux sites, located at the University of Nebraska-Lincoln's 
(UNL) Agricultural Research and Development Center (ARDC) near Mead, Nebraska, have the complete data from 2001 to 2012 for model calibration and validation. Specifically, the hourly gap-filled meteorological variables (i.e., precipitation, humidity, air temperature, downward shortwave radiation, and wind speed) are obtained from AmeriFlux; the soil information of 12 soil layers with a maximum root-zone depth of $2.0 \mathrm{~m}$ (i.e., field capacity, wilting point, soil texture, saturated hydraulic conductivity, bulk density, soil organic carbon, $\mathrm{pH}$, and cation exchange capacity) is obtained from the Gridded Soil Survey Geographic Database (gSSURGO) dataset (NRCS, 2010); eddy-covariance fluxes (i.e., gross primary productivity (GPP), net ecosystem exchange (NEE), and LE) are provided by the FLUXNET2015 Tier 1 dataset (http://fluxnet.fluxdata.org/data/fluxnet2015-dataset/); and the detailed ground-based crop growth observations (i.e., planting/harvest date, planting density, irrigation/fertilization records, LAI, and yield) can be obtained from the Carbon Sequestration Program (CSP) at UNL-ARDC (http://csp.unl.edu/Public/sites.htm; Peng et al., 2018). US-Ne1 site is an irrigated site with continuously maize cropping system during 2001-2012; US-Ne2 site is also irrigated but with maize-soybean rotation cropping system during 2001-2009 and then continuous maize cropping system during 2010-2012; and US-Ne3 site is rainfed with maize-soybean rotation cropping system during 2001-2012. Two parameters of ecosys, including fraction of leaf protein in bundle sheath chlorophyll (CHL4) and plant maturity group (GROUPX), were calibrated for minimizing RMSE between simulations and observations (GPP, ET, LAI, and yield) at US-Ne1, US-Ne2, and US-Ne3 in odd maize years from 2001 to 2012, and the calibrated parameters were used for model validation with the observations in even maize years from 2001 to 2012.

For the 12 irrigated sites with a dramatic rainfall gradient across Nebraska, the hourly meteorological variables (i.e., precipitation, humidity, air temperature, downward shortwave radiation, and wind speed) from the North American Land Data Assimilation System (NLDAS-2) and soil information of 12 soil layers with a maximum root-zone depth of $2.0 \mathrm{~m}$ from gSSURGO were used to drive ecosys. The planting date of the continuous maize cropping systems at the 12 sites was obtained from the USDA NASS weekly Crop Progress Reports (2001-2019) with the fertilizer (18 $\mathrm{g} \mathrm{N} \mathrm{m}^{-2}$ and $\left.5 \mathrm{~g} \mathrm{P} \mathrm{m}^{-2} / \mathrm{yr}\right)$ applied 2 days before planting, and the crops were harvested on October 31. Other land management practices were set as the same across the 12 irrigated sites in Nebraska, including planting density $\left(8.4\right.$ plants $\mathrm{m}^{-2}$ ), tillage practice (no tillage), and crop type (continuous maize cropping systems). The auto-irrigation scheme in ecosys with the widely used soil-based MAD-50\% in the top 9 soil layers (0.92 m; i.e., irrigation was triggered to fill current soil moisture to field capacity when MAD increased above a threshold of 0.5 ) was applied to determine the irrigation scheduling at 12 sites for calibration and validation (Malejane et al., 2018). To minimize the impacts of crop yields technology trend (Najafi et al., 2018), that is, the technological advances (such as seeds and fertilizer improvements) to increase crop yields, the NASS county-level irrigated maize yield in recent 10 years (2010-2019) at the counties where the 12 sites were located was used as the observations for model calibration and validation. Similar to three AmeriFlux sites, we calibrated two parameters (CHL4 and GROUPX) of ecosys for minimizing RMSE between simulated and the NASS county-level irrigated maize yield in odd years from 2010 to 2019, and directly used the calibrated parameters for model validation in even years from 2010 to 2019.

\subsection{Irrigation Assessment Framework}

The ecosys model was applied at the 12 sites across Nebraska to study different PWS metrics and to assess their efficacy for guiding irrigation during the period from 2001 to 2019. Irrigation was triggered when the PWS metric reached its triggering threshold, and we assumed that irrigation amount equals the amount of water needed to refill the root-zone soil moisture to field capacity, ignoring the constraints from irrigation infrastructures. In addition, each irrigation event lasted for $24 \mathrm{~h}$, and was incorporated into the ecosys model on a daily basis in real time. There were two types of thresholds for six PWS metric-based irrigation schemes: universal (same threshold without spatial variation) and site-specific (different thresholds with spatial variation). These two types of triggering thresholds were optimized by maximizing economic profits (Equation 13) through the irrigation assessment framework using trial and error approach with the threshold samples from their reasonable ranges. For their reasonable ranges (Malejane et al., 2018; Moriana et al., 2012; Panda et al., 2004), the samples of MAD ranged from 0.35 to 0.65 with a step of 0.05 ; those of CWP ranged from -4.0 to $-0.5 \mathrm{MPa}$ with a step of $0.5 \mathrm{MPa}$; those of $g_{\mathrm{s}}$ ranged from 0.0003 to $0.0045 \mathrm{~m} \mathrm{~s}^{-1}$ with a step of $0.0003 \mathrm{~m} \mathrm{~s}^{-1}$; and those of CWSI, ESI, and TSI ranged from 0.1 to 0.9 with a step of 0.1 . 
Table 1

Parameters Used in the Irrigation Assessment Framework

\begin{tabular}{|c|c|c|c|}
\hline Parameter & Description & Source & Value \\
\hline Y & Yield of maize ( $\mathrm{t}$ ha-1) & Ecosys model simulation & - \\
\hline$p_{\text {maize }}$ & Price of maize ( $\$$ ha-1) & $\begin{array}{l}\text { USDA NASS (https://www.nass.usda.gov/Quick_Stats/Lite/index. } \\
\text { php) }\end{array}$ & 149.99 \\
\hline$I$ & Irrigation amount (mm) & Ecosys model simulation & - \\
\hline$\Gamma_{\text {irrigation }}$ & Cost of irrigation costs, including fuel and labor $\left(\$ \mathrm{~m}^{-3}\right)$ & 2019 Nebraska Crop Budgets (https://cropwatch.unl.edu/budgets) & 0.095 \\
\hline$\lambda$ & Irrigation application efficiency of the center pivots & $\begin{array}{l}\text { U. S. Government Accountability Office (https://www.gao.gov/ } \\
\text { products/GAO-20-128SP) }\end{array}$ & 0.85 \\
\hline$K_{\text {fixed }}$ & $\begin{array}{l}\text { Fixed costs of production, including seed, fertilizer, } \\
\text { herbicide, crop insurance, and so on }\left(\$ \mathrm{ha}^{-1}\right)\end{array}$ & 2019 Nebraska Crop Budgets (https://cropwatch.unl.edu/budgets) & $1,247.86$ \\
\hline
\end{tabular}

Economic profit was the net revenue based on marketable yields and costs, including irrigation costs and fixed costs of production. Furthermore, we used irrigation water productivity to evaluate the water saving effects of the PWS metrics with similar crop yields and economic benefits. Irrigation water productivity was the ratio of marketable yields to irrigation amount during the growing season (Equation 14; Fernández et al., 2020). To reduce the impacts of parameters in the irrigation assessment framework, we used the recorded parameters in 2019 at Nebraska (Table 1).

$$
\begin{gathered}
\text { Profit }=\text { Revenue }- \text { Costs }=y \times p_{\text {maize }}-\frac{I}{\lambda} \times \Gamma_{\text {irrigation }}-K_{\text {fixed }}, \\
I W P=\frac{y}{I},
\end{gathered}
$$

where $y$ is the yield of maize $\left(\mathrm{t} \mathrm{ha}^{-1}\right) ; p_{\text {maize }}$ is the price of maize $\left(\$ \mathrm{t}^{-1}\right)$; $\boldsymbol{I}$ is the irrigation amount $(\mathrm{mm})$; $\Gamma_{\text {irrigation }}$ is the price of irrigation $\left(\$ \mathrm{~m}^{-3}\right) ; \lambda$ is the irrigation application efficiency of the center pivots; $\boldsymbol{K}_{\text {fixed }}$ is the fixed costs of production $\left(\$ \mathrm{ha}^{-1}\right)$, including the costs of seeds, fertilizer, storage, and so on (Table 1); and IWP is the irrigation water productivity $\left(\mathrm{kg} \mathrm{m}^{-3}\right)$.

\section{Results}

With the validated process-based model (ecosys), we investigated their interconnections and described the co-regulation of soil water supply and atmospheric water demand on six PWS metrics. Then, six PWS metrics were implemented to guide irrigation using ecosys as different irrigation schemes. We determined the optimal triggering thresholds for six PWS metrics through the irrigation assessment framework, and assessed their efficacy across 12 sites with a dramatic rainfall gradient in Nebraska during 2001-2019, that is, 228 site-yr.

\subsection{Ecosys Model Performance}

We have rigorously calibrated and validated the ecosys model at three AmeriFlux sites (US-Ne1, US-Ne2, and US-Ne3) and 12 sites with a dramatic rainfall gradient across Nebraska (Figures 4, S1, S2, and Table S2). For three AmeriFlux sites (US-Ne1, US-Ne2, and US-Ne3), the daily ecosys-simulated GPP, ET, and LAI of maize cropping systems matched very well with the eddy-covariance and ground-based observations in calibration (Figures S2a-S2c) and validation (Figures $4 \mathrm{a}-4 \mathrm{c}$ ). The $R^{2}$ of daily GPP, ET, and LAI in validation were $0.84,0.82$, and 0.78 , respectively, and the RMSE of daily GPP, ET, and LAI in validation were $3.75 \mathrm{~g} \mathrm{C} \mathrm{m}^{-2}$ day $^{-1}, 0.83 \mathrm{~mm} \mathrm{day}^{-1}$, and $1.06 \mathrm{~m}^{2} \mathrm{~m}^{-2}$, respectively (Table $\mathrm{S} 2$ ). Taken US-Ne1 with continuous maize cropping systems as an example, ecosys could capture the magnitude and seasonal patterns of carbon, 
(a) GPP (daily) at US-Ne1, Ne2, Ne3

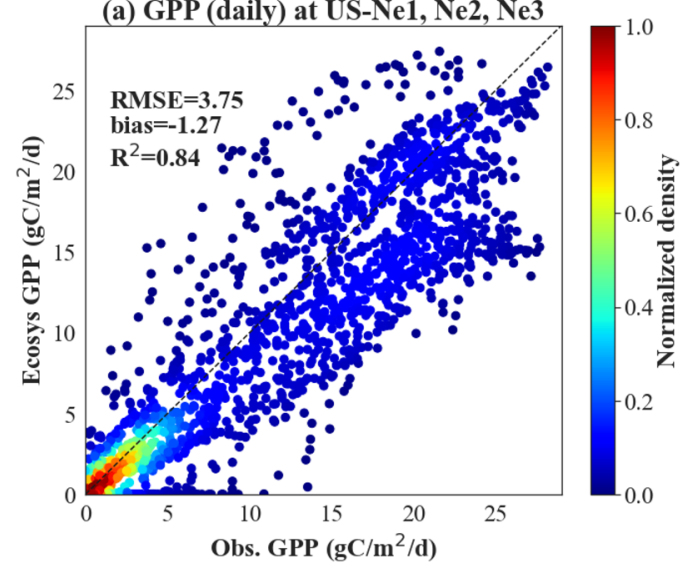

(c) LAI (daily) at US-Ne1, Ne2, Ne3

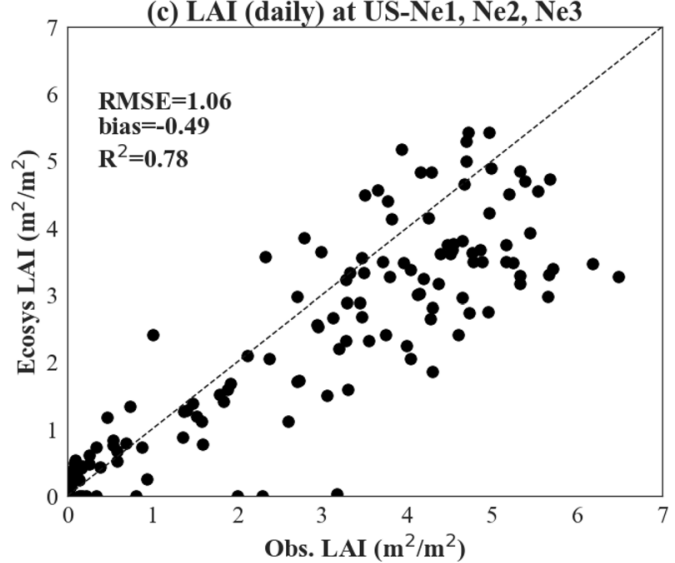

(e) Yield at 12 sites (even years)

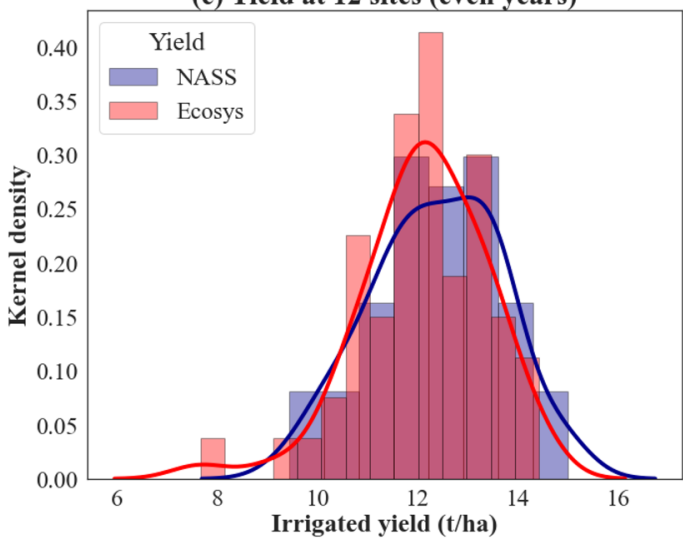

(b) ET (daily) at US-Ne1, Ne2, Ne3

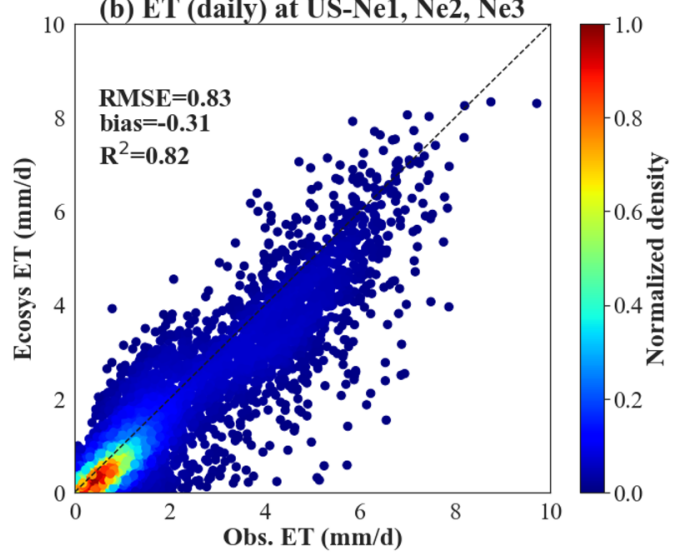

(d) Yield at US-Ne1, Ne2, Ne3

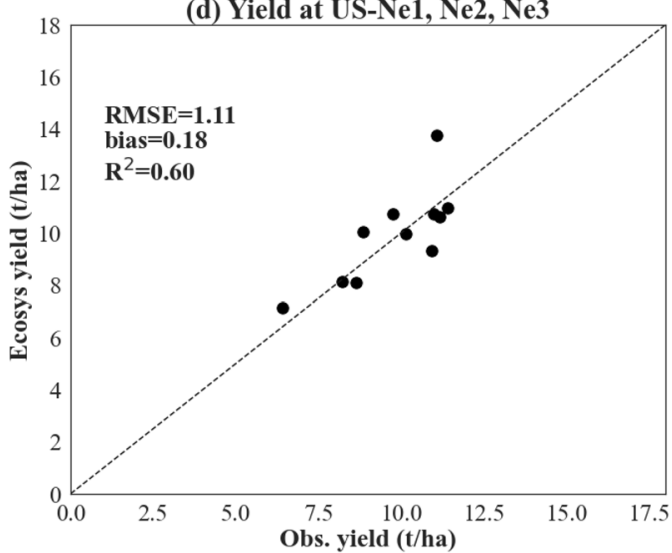

Figure 4. The validated performance of the ecosys model with maize cropping systems at (a-d) three AmeriFlux sites (US-Ne1, US-Ne2, and US-Ne3, the even maize years from 2001 to 2012) and (e) 12 sites with a dramatic rainfall gradient across Nebraska (the even years from 2010 to 2019). The color bar shows the normalized Gaussian kernel density estimation of the scatters. Black dashed lines indicate the one-to-one relationship. The probability density function of the maize yields at the 12 sites is the Gaussian kernel density estimation.

energy, and water fluxes with high accuracy (Figure S1). For crop yields, the ecosys-simulated maize yields generally showed good agreement with the CSP observations, as bias was less than $0.7 \%$ and $1.8 \%$ of averaged maize yields observations in calibration $\left(R^{2}=0.46\right.$, Figure S2d) and validation $\left(R^{2}=0.60\right.$, Figure $\left.4 \mathrm{~d}\right)$, respectively. For the 12 sites with a dramatic rainfall gradient across Nebraska, we used the probability density function with Gaussian kernel density estimation to describe the calibrated and validated performance 


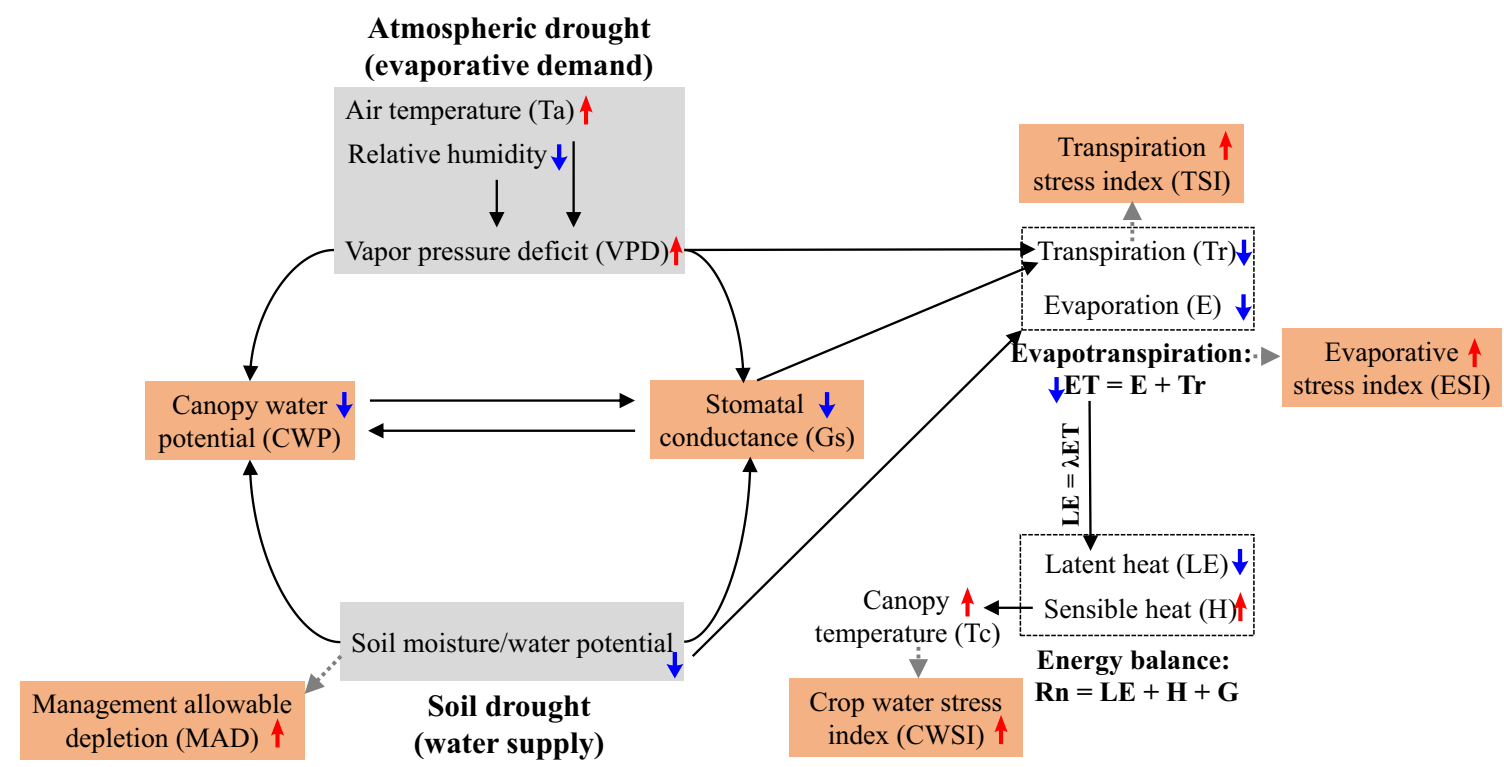

Figure 5. The schematic diagram of the main processes by which atmospheric and soil drought (gray background) affects six PWS metrics (orange background) in SPAC ultimately. Red arrow denotes the increasing trend, while the blue arrow denotes a decreasing trend. This diagram is revised based on Figure 1A in Buckley (2017).

due to unavailable detailed observations. The probability density function of the ecosys-simulated irrigated maize yields showed good agreement with that of the NASS county-level irrigated yields in calibration (odd years during 2010-2019, Figure S2e) and validation (even years during 2010-2019, Figure 4e). In addition, the ecosys model has been validated its abilities to capture the carbon cycle dynamics to environmental variability, including soil moisture and VPD, at both site and region scales in the United States Midwest (Zhou et al., 2021). GPP and crop yield increase with VPD when VPD is small, but decrease with increasing VPD when VPD gets higher due to the negative impacts of VPD on stomatal conductance. The sensitivity of carbon cycle dynamics to soil moisture is similar to that to VPD, but arising from the trade-off between soil water supply and oxygen stress at high soil moisture (see more details in Zhou et al., 2021). All these results confirmed the reliability of ecosys for this study.

\subsection{PWS Metrics Analysis}

The theoretical analysis of plant water relations in SPAC shows the main processes by which atmospheric and soil drought affects six PWS metrics ultimately and their interconnections (Figure 5). The water stress from both soil drought (i.e., increased MAD) and atmospheric drought leads to stomatal closure, that is, decreased stomatal conductance ( $G_{\mathrm{s}}$, Equation 15), and a decline in CWP (i.e., decreased CWP) through some direct stress and/or the plant hydraulics in SPAC (Buckley, 2017; Herve, 2014). Stomatal closure could reduce the plant transpiration (i.e., increased TSI) ultimately under low soil moisture and high VPD conditions with the equilibrium of plant transpiration and root water uptake in the steady state due to water balance in SPAC (Equation 16; Grossiord et al., 2020; López et al., 2021; Massmann et al., 2019). Meanwhile, decreased ET (i.e., increased ESI) could reduce latent heat (Equation 17) and increase sensible heat (Equation 18) under energy balance in SPAC (Equation 9), thus increasing canopy temperature (i.e., increased CWSI).

$$
\begin{gathered}
r_{c}=\frac{1}{G_{s}}, \\
U=T_{r}=\frac{\psi_{c}-\psi_{s}}{r_{s}+r_{r}+r_{a}},
\end{gathered}
$$




$$
\begin{gathered}
L E=\lambda E T=\frac{\rho C_{p}}{\gamma} \frac{\left(e_{T_{c}}^{*}-e_{a}\right)}{r_{b}+r_{c}}=\frac{\rho C_{p}}{\gamma} \frac{V P D}{r_{b}+r_{c}}, \\
H=\frac{\rho C_{p}}{r_{b}}\left(T_{c}-T_{a}\right),
\end{gathered}
$$

where $U$ is root water uptake; $\psi_{\mathrm{c}}$ and $\psi_{\mathrm{s}}$ are canopy and soil water potential, respectively; $r_{\mathrm{s}}$ is the radial resistances from soil to root surfaces; $r_{\mathrm{r}}$ is the radial resistances from root surfaces to root axes; $r_{\mathrm{a}}$ is the axial resistances from root axes to canopy; $\lambda$ is the latent heat of vapourization $\left(\mathrm{J} \mathrm{kg}^{-1}\right) ; \rho$ is the density of air $\left(\mathrm{kg} \mathrm{m}^{-3}\right) ; C_{\mathrm{p}}$ is the heat capacity of air $\left(\mathrm{J} \mathrm{kg}^{-1}{ }^{\circ} \mathrm{C}^{-1}\right) ; \gamma$ is the psychrometric constant $\left(\mathrm{Pa}^{\circ} \mathrm{C}^{-1}\right) ; e_{T_{C}}^{*}$ is the saturated vapor pressure $(\mathrm{Pa})$ at the canopy temperature $\left(T_{\mathrm{c}}\right) ; e_{\mathrm{a}}$ is the actual vapor pressure $(\mathrm{Pa})$; and $r_{\mathrm{b}}$ and $r_{\mathrm{c}}$ are the canopy boundary layer resistance and canopy stomatal resistance, respectively.

We used ecosys to quantify the interconnections among six PWS metrics, then described their abilities in capturing water constraints from water supply and demand, that is, the co-regulation of soil water supply and atmospheric water demand. The CWP, $G_{\mathrm{S}}$ (canopy-level stomatal conductance), CWSI, ESI, TSI, and MAD at the daily step during the peak growing season (July and August, to reduce the impacts of LAI) across 228 site-yr in Nebraska were calculated for PWS metrics analysis based on the simulations of ecosys without irrigation. $T_{\mathrm{r}_{-} \mathrm{ww}}$ and $\mathrm{ET}_{\mathrm{ww}}$ were obtained from the ecosys model assuming no PWS. Daily root-zone soil moisture and VPD were calculated to represent soil water supply and atmospheric water demand.

\subsubsection{Interconnections of Different PWS Metrics}

We used the bivariate analysis with the Spearman correlation to investigate the interconnections among six PWS metrics simulated using ecosys. Taking site-NPL in central Nebraska as an example (Figure 6), the Spearman's rank correlation coefficients among the plant-centric metrics (CWP, $G_{\mathrm{S}}$, CWSI, ESI, and TSI; larger than 0.68) were relatively larger than those between the plant-centric metrics and the soil-based metric (MAD; smaller than 0.68). Specifically, CWP and $G_{S}$ had the highest Spearman's rank correlation coefficient (0.92), indicating that they were coupled tightly with strong monotonic relationships. These results indicated that the plant-centric metrics were highly interconnected, and the solely soil-based metric (MAD) reflected limited information of PWS, further underscoring the importance of the plant-centric metrics. In addition, the Spearman's rank correlation coefficients between TSI and other PWS metrics were slightly higher than those between ESI and other PWS metrics. The reason was that ESI incorporated the information of soil evaporation, while TSI was completely based on the plant itself.

\subsubsection{The Co-Regulation of Soil Water Supply and Atmospheric Water Demand}

After the analysis of the interconnections among six PWS metrics, we investigated the connections between six simulated PWS metrics and the water constraints from water supply and demand, that is, the co-regulation of soil water supply and atmospheric water demand. First, the Spearman partial rank correlation coefficients between six PWS metrics and soil moisture/VPD across the 228 site-yr in Nebraska were calculated (Figure 7). All the Spearman partial rank correlation coefficients between five plant-centric metrics and soil moisture/VPD were significant $(p<0.001$ ), demonstrating the controls from soil moisture and VPD on five plant-centric metrics (CWP, $G_{S}$, CWSI, ESI, and TSI). The coefficients of CWP and $G_{\mathrm{S}}(0.73$ and 0.67 with soil moisture, and -0.56 and -0.43 with VPD) were relatively higher than those of other plant-centric metrics (CWSI, ESI, and TSI). This indicated that CWP and $G_{\mathrm{S}}$ could reflect more information on the variation of both soil moisture and VPD. In contrast, CWSI reflected the least information of soil moisture and VPD among five plant-centric metrics with the lowest coefficients. The coefficients of ESI and TSI were close to each other and both relatively larger than those of CWSI. This indicated that ESI and TSI had comparable performances to interpret water supply and demand during the peak growing season due to high vegetation cover fraction and thus low soil water evaporation. Besides, the soil-based metric, MAD, which was solely determined by soil moisture, had the highest coefficient with soil moisture and its coefficient with VPD was close to 0 . 


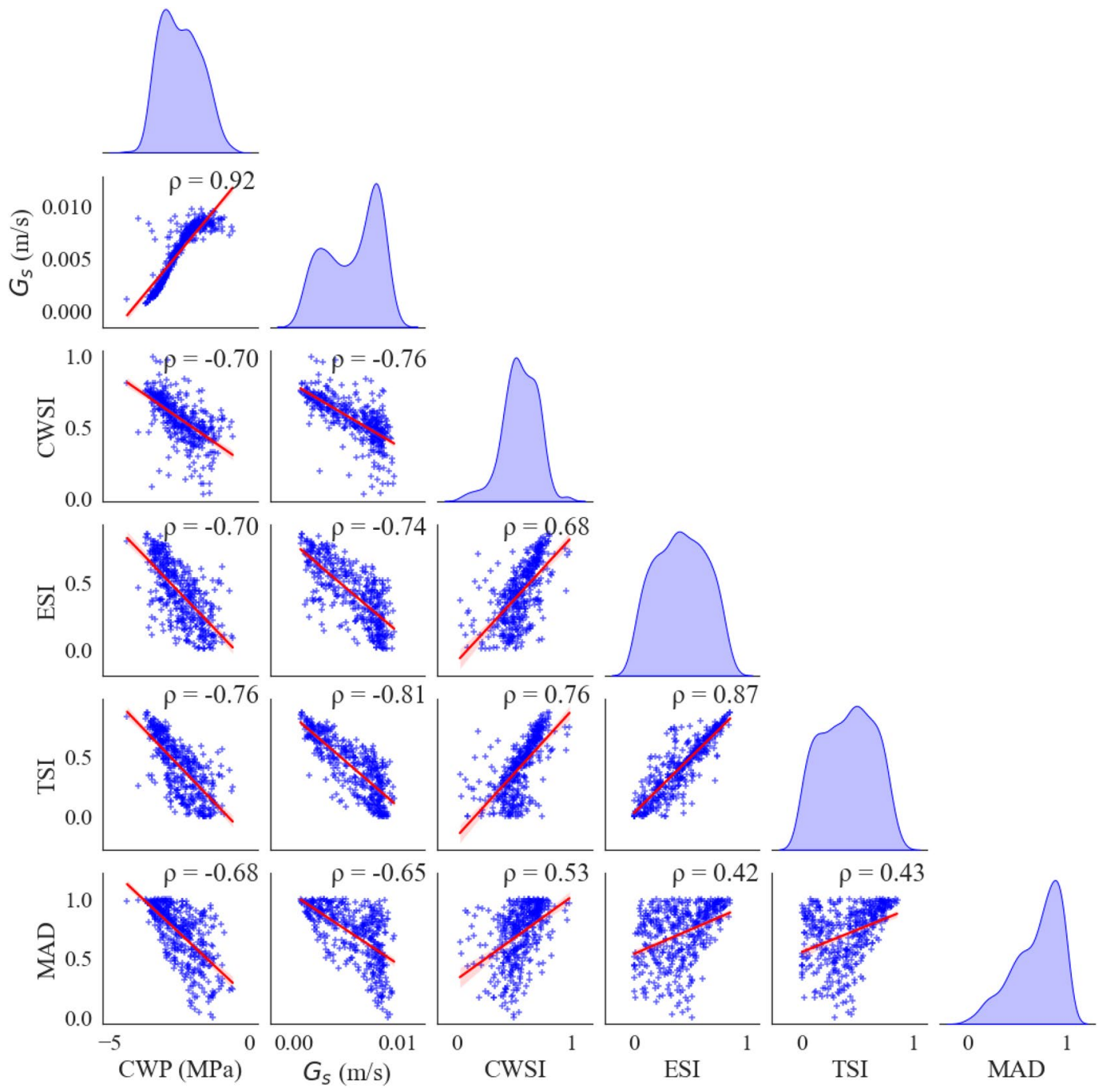

Figure 6. The interconnections among six PWS metrics simulated using ecosys during the peak growing season (July and August) from 2001 to 2019 at an example site-NPL in central Nebraska. The probability density functions in the diagonal grid are the kernel density estimation of six PWS metrics. $\rho$ denotes the Spearman's rank correlation coefficient.

Spearman partial rank correlation

\section{Soil moisture (control VPD impact) VPD (control soil moisture impact)}

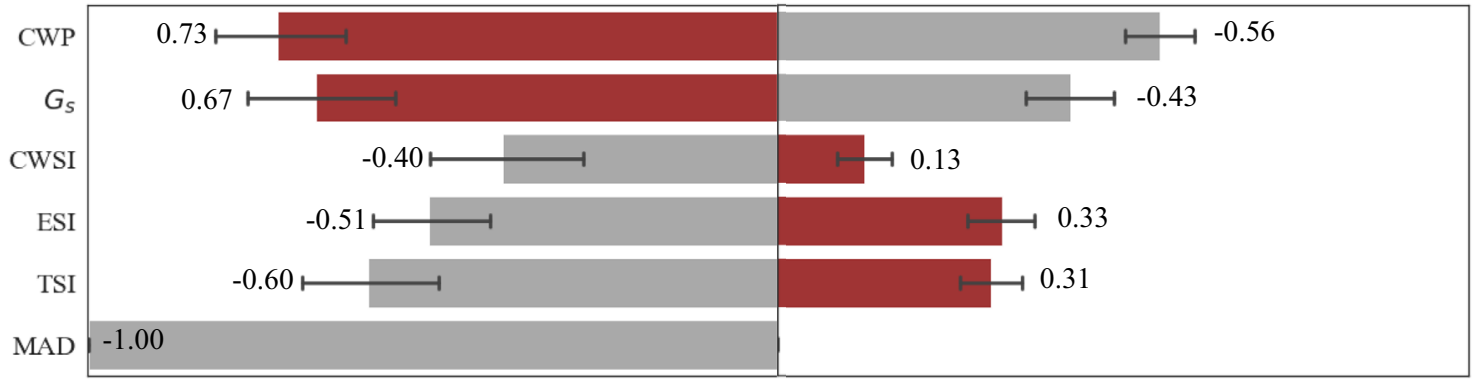

Figure 7. The Spearman partial rank correlation coefficients between six simulated PWS metrics and soil moisture/VPD during the peak growing season (July and August) across the 228 site-yr in Nebraska. Red and gray color denotes the positive and negative Spearman partial rank correlation coefficients. The black bar denotes the standard deviation of the coefficients (black numbers near the bars) across the 228 site-yr. 


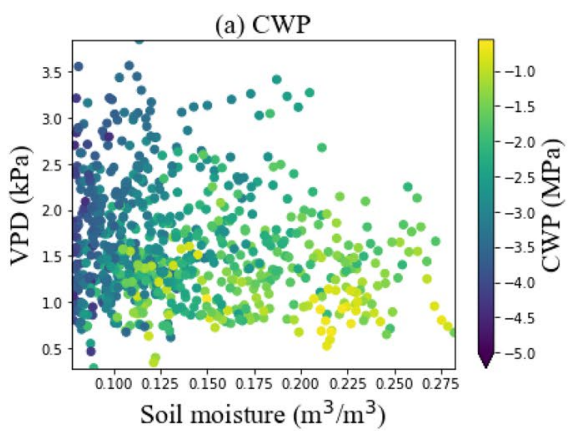

(d) ESI

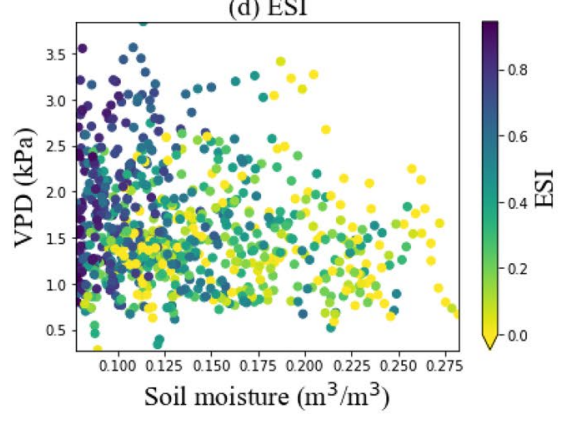

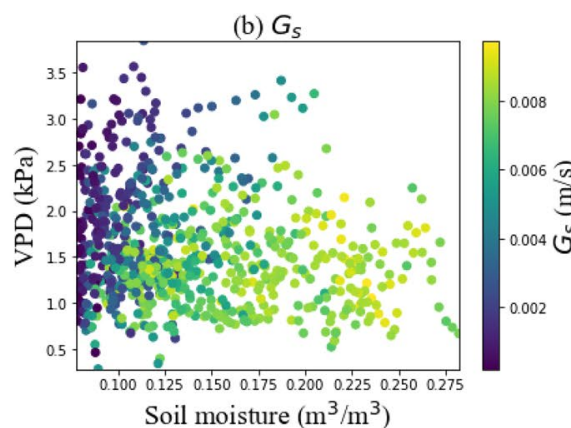

(e) TSI

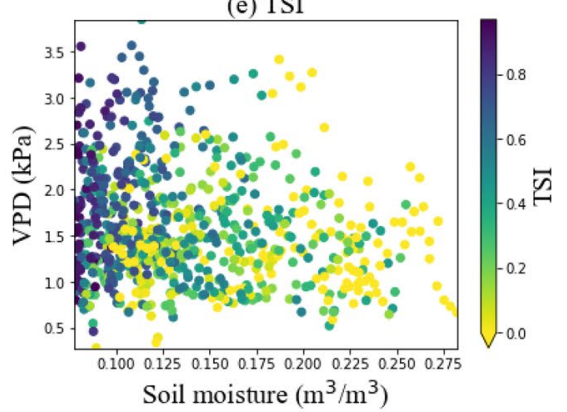

(c) CWSI

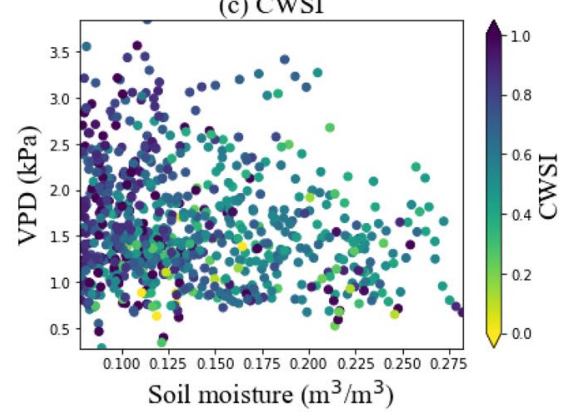

(f) MAD

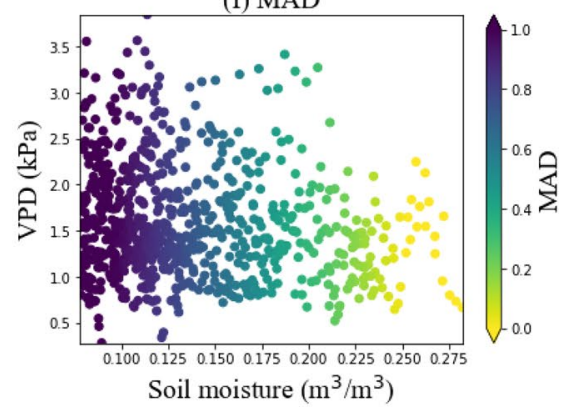

Figure 8. The co-regulation of soil moisture and VPD on six simulated PWS metrics at an example site-NPL in central Nebraska during the peak growing seasons (July and August) from 2001 to 2019. The color bar denotes the magnitude of the PWS metrics.

Second, the scatters of soil moisture and VPD with six PWS metrics were applied to show the co-regulation patterns. Taking site-NPL in central Nebraska as an example (Figure 8), different PWS metrics showed different co-regulation patterns. Both CWP and $G_{\mathrm{S}}$ reflected the clear co-regulation patterns of soil moisture and VPD (Figures 8a and 8b), especially Figure 7 in Zhang et al. (2021). Specifically, CWP and $G_{\mathrm{S}}$ increased with soil moisture given specific VPD conditions, while they decreased with VPD given specific soil moisture. ESI and TSI could also reflect the co-regulation patterns but with some extremes (Figures 8d and 8e). The extremes may be caused by other factors, such as radiation and nutrients, other than water. CWSI showed a disordered co-regulation pattern of soil moisture and VPD, which further demonstrated that it had the smallest Spearman partial rank correlation coefficients with soil moisture and VPD (Figure 8c). Regarding the soil-based metric, MAD, there was only a regulation pattern of soil moisture without reflecting the information of VPD (Figure 8f).

We further used a relative importance method-Lindeman, Merenda, and Gold (LMG; Grömping, 2006, 2007) to quantify the relative contributions of soil moisture and VPD on five plant-centric metrics $\left(\mathrm{CWP}, G_{\mathrm{S}}\right.$, CWSI, ESI, and TSI), and also analyzed their spatial variation across the 12 sites in Nebraska (Figure 9). The LMG method decomposed the determination coefficients of a linear regression $\left(R^{2}\right)$ to the contributions of soil moisture and VPD, that is, to quantify the variation of five plant-centric metrics that could be explained by soil moisture and VPD, while taking the correlation between soil moisture and VPD into account. The estimated relative importance of soil moisture on the five plant-centric metrics increased with the aridity index (the ratio of potential ET, PET, and precipitation, P, in the growing season during 2001-2019, i.e., PET/P, Figure 9a), while those of VPD decreased with the increasing aridity index (Figure 9b). This indicated that soil moisture made larger contributions to the variations of five plant-centric metrics in drier regions, such as western Nebraska, while VPD made larger contributions to the variations of five plant-centric metrics in wetter regions, such as eastern Nebraska. It should be noted that CWSI had the lowest relative importance of VPD among six metrics across the 12 sites in Nebraska, indicating that CWSI reflected little information about VPD. 
(a)

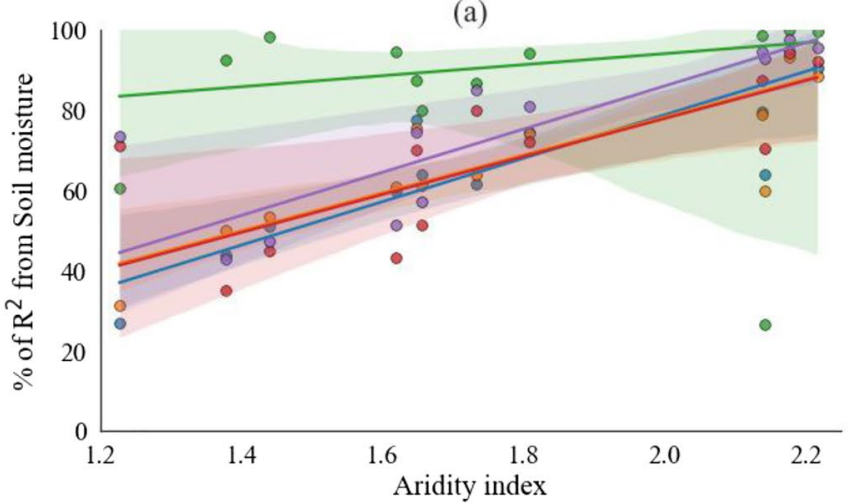

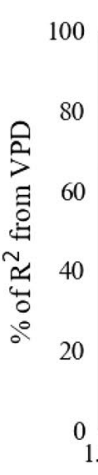

(b)

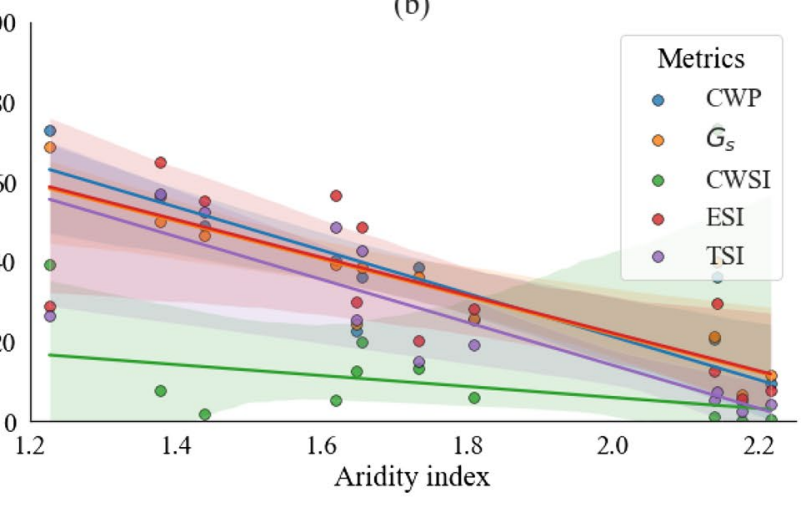

Figure 9. Variation of the relative importance estimates of (a) soil moisture and (b) VPD on five plant-centric metrics with aridity index across the 12 sites in Nebraska during the peak growing seasons (July and August) from 2001 to 2019. The line denoted the regression line with a 95\% confidence interval.

\subsection{Performance of Different PWS Metrics-Based Irrigation Schemes}

\subsubsection{Optimal Triggering Thresholds}

The site-specific and universal triggering thresholds of six PWS metrics were selected with the maximum averaged economic profits (details in Section 3.3, Table 2). It should be noted that the leaf-level stomatal conductance $\left(g_{s}\right)$ was used here to avoid the impact of LAI during the whole growing season. As $g_{s}$ is highly dynamic and impacted by multiple factors in addition to water, such as nutrients, radiation, air temperature, and $\left[\mathrm{CO}_{2}\right]$ (Buckley \& Mott, 2013), it may be inappropriate to use daily $g_{\mathrm{s}}$ near midday to trigger irrigation directly even with its effective abilities to indicate PWS from both soil water deficit and atmospheric aridity. There are some days with low $g_{s}$ but high soil moisture due to the stress from other environmental factors than water, while irrigation will be triggered if we only use $g_{\mathrm{s}}$ as the trigger metric. Under these conditions with low $g_{s}$ but no water stress, irrigation has little benefit for crop growth but large damage to economic profits. We suggested adding the constraint of soil moisture with the optimized triggering threshold of MAD to $g_{s}$ to make the GS_MAD-based irrigation scheme. In this case, irrigation was triggered on any day when both $g_{s}$ and soil moisture were lower than the critical $g_{s}$ and the optimized triggering threshold of MAD, respectively, thus irrigation could be saved on the days with low $g_{s}$ but high soil moisture. In addition, site-specific triggering thresholds were optimized for each site with the site-specific climate and soil properties individually (Table 2).

Table 2

Optimal Triggering Thresholds of Six Metrics-Based Irrigation Schemes

\begin{tabular}{lccccccc}
\hline Sites & & MAD & CWP $(\mathrm{MPa})$ & $g_{\mathrm{s}}$ in GS_MAD $\left(\mathrm{m} \mathrm{s}^{-1}\right)$ & CWSI & ESI & TSI \\
\hline Site-specific & Mead & 0.60 & -3.0 & 0.0018 & 0.1 & 0.7 & 0.7 \\
& GD & 0.55 & -3.0 & 0.0030 & 0.2 & 0.8 & 0.7 \\
& Harvard & 0.60 & -2.5 & 0.0027 & 0.1 & 0.7 & 0.7 \\
& Lowell & 0.60 & -3.5 & 0.0024 & 0.1 & 0.7 & 0.7 \\
& Sheridan & 0.60 & -2.0 & 0.0042 & 0.1 & 0.7 & 0.7 \\
& Dawson & 0.60 & -2.5 & 0.0039 & 0.1 & 0.7 & 0.7 \\
& NPL & 0.60 & -2.5 & 0.0039 & 0.1 & 0.5 & 0.5 \\
& PH3 & 0.55 & -2.5 & 0.0033 & 0.1 & 0.6 & 0.6 \\
& T1S4 & 0.60 & -2.5 & 0.0036 & 0.1 & 0.6 & 0.6 \\
& T1S1 & 0.60 & -3.0 & 0.0033 & 0.1 & 0.6 & 0.5 \\
Universal & East Bayard & 0.45 & -2.5 & 0.0036 & 0.1 & 0.6 & 0.6 \\
& Mitchell & 0.55 & -2.5 & 0.0027 & 0.1 & 0.7 & 0.7 \\
& & 0.60 & -2.5 & 0.0042 & 0.1 & 0.7 & 0.7 \\
\hline
\end{tabular}


Table 3

The Averaged Economic Profits $\left(\$ \mathrm{Ha}^{-1}\right)$ of Six Metrics-Based Irrigation Schemes With Site-Specific and Universal Triggering Thresholds Across the 12 Sites in Nebraska During 2001 to 2019

\begin{tabular}{|c|c|c|c|c|c|c|c|c|c|c|c|c|c|c|c|}
\hline Schemes & & Mead & GD & Harvard & Lowell & Sheridan & Dawson & NPL & PH3 & T1S4 & T1S1 & East Bayard & Mitchell & Mean & Rank \\
\hline \multirow[t]{2}{*}{ MAD } & Site-specific & 539.8 & 553.6 & 498.5 & 112.6 & 481.9 & 460.6 & 454.5 & 328.1 & 324.6 & 323.6 & 93.3 & 4.9 & 348.0 & 3 \\
\hline & Universal & 539.8 & 548.1 & 498.5 & 112.6 & 481.9 & 460.6 & 454.5 & 324.9 & 324.6 & 323.6 & 89.9 & 2.5 & 346.8 & \\
\hline \multirow[t]{2}{*}{ CWP } & Site-specific & 580.2 & 570.9 & 513.3 & 107.0 & 501.6 & 490.6 & 473.5 & 345.8 & 341.3 & 330.8 & 119.4 & 3.6 & 364.8 & 1 \\
\hline & Universal & 574.2 & 567.8 & 513.3 & 87.7 & 498.6 & 490.6 & 473.5 & 345.8 & 341.3 & 316.1 & 119.4 & 3.6 & 361.0 & \\
\hline \multirow[t]{2}{*}{ GS_MAD } & Site-specific & 564.1 & 569.9 & 506.4 & 116.6 & 505.0 & 489.5 & 464.1 & 327.6 & 346.1 & 338.0 & 101.3 & 9.4 & 361.5 & 2 \\
\hline & Universal & 544.6 & 563.6 & 504.0 & 112.6 & 505.0 & 488.9 & 463.0 & 330.1 & 342.2 & 333.5 & 90.5 & 2.5 & 356.7 & \\
\hline \multirow[t]{2}{*}{ CWSI } & Site-specific & 540.8 & 540.2 & 464.8 & 104.6 & 462.9 & 345.8 & 379.1 & 265.5 & 225.3 & 88.2 & 44.4 & 0.0 & 288.5 & 6 \\
\hline & Universal & 540.8 & 540.7 & 464.8 & 104.6 & 462.9 & 345.8 & 379.1 & 265.5 & 225.3 & 88.2 & 44.4 & 0.0 & 288.5 & \\
\hline \multirow[t]{2}{*}{ ESI } & Site-specific & 564.6 & 555.2 & 499.2 & 101.1 & 463.7 & 443.0 & 410.4 & 301.3 & 265.3 & 268.6 & 77.1 & 2.0 & 329.3 & 4 \\
\hline & Universal & 564.6 & 544.2 & 499.2 & 101.1 & 463.7 & 443.0 & 407.5 & 297.9 & 273.1 & 264.7 & 66.2 & 2.0 & 327.3 & \\
\hline \multirow[t]{2}{*}{ TSI } & Site-specific & 568.1 & 566.4 & 511.5 & 105.1 & 460.5 & 437.7 & 398.6 & 301.1 & 253.4 & 260.2 & 68.8 & 2.4 & 327.8 & 5 \\
\hline & Universal & 568.1 & 566.4 & 511.5 & 105.1 & 460.5 & 437.7 & 397.1 & 293.0 & 235.6 & 267.0 & 57.9 & 2.4 & 325.2 & \\
\hline
\end{tabular}

Note. The order of sites from left-Mead to right-Mitchell denotes the decreasing annual rainfall from $900 \mathrm{~mm}$ in the east to $350 \mathrm{~mm}$ in the west.

\subsubsection{Irrigation Scenario Assessment}

Here, we systematically tested six PWS metrics-based irrigation schemes with optimal site-specific and universal thresholds across the 12 sites with a dramatic rainfall gradient in Nebraska during 2001-2019 (Table 3). We ranked six PWS metrics-based irrigation schemes based on the averaged economic profits across the 228 site-yr (Table 3). The CWP-based irrigation scheme had the largest averaged economic profits, followed by the GS_MAD-based irrigation scheme (Figure 10 and Table 3). These results indicated that the plant-centric irrigation schemes from plant hydraulics and stomatal response, the direct mechanisms related to plant water relations in SPAC, could achieve better performance than the soil-based irrigation scheme (MAD), while the other three plant-centric irrigation schemes (CWSI, ESI, and TSI) had lower averaged economic profits. For ESI and TSI-based irrigation schemes, as soil water evaporation was relatively small when the vegetation cover fraction became larger, their performances were close to each other, and both were superior to the CWSI-based irrigation scheme. Six PWS metrics-based irrigation schemes with site-specific thresholds had relatively higher economic profits than those with universal thresholds due to the specific climate and soil properties, while irrigation schemes with universal thresholds were more flexible (Table 3).
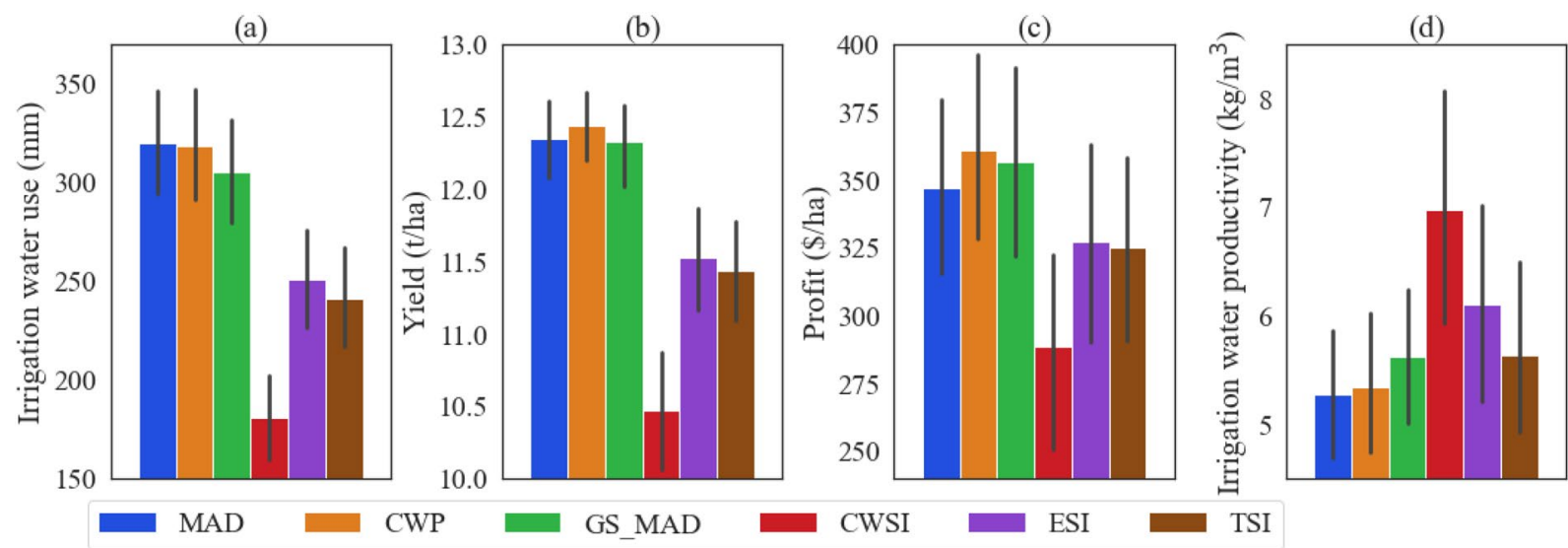

Figure 10. Irrigation water use, yield, profit, and irrigation water productivity of six PWS metrics (MAD, CWP, GS_MAD, CWSI, ESI, and TSI) based irrigation schemes with universal thresholds across the 228 site-yr in Nebraska. The black bar denotes the standard deviation of these variables. 
The performance of six PWS metrics-based irrigation schemes was indicated by the averaged irrigation water use, crop yields, economic profits, and irrigation water productivity across the 228 site-yr in Nebraska with universal thresholds (Figure 10). Compared to the soil-based MAD irrigation scheme, five plant-centric irrigation schemes (CWP, GS_MAD, CWSI, ESI, and TSI) could significantly reduce irrigation water use and increase irrigation water productivity. Specifically, the CWP-based irrigation scheme could increase crop yields $\left(+1.3 \%,+0.1 \mathrm{t} \mathrm{ha}^{-1}\right)$, economic profit $\left(+7.6 \%,+\$ 14.2 \mathrm{ha}^{-1}\right)$, and irrigation water productivity $\left(+6.6 \%,+0.3 \mathrm{~kg} \mathrm{~m}^{-3}\right)$ with less irrigation water use $(-1.1 \%,-1.4 \mathrm{~mm})$. The GS_MAD-based irrigation scheme could significantly reduce irrigation water use $(-5.2 \%,-14.4 \mathrm{~mm})$ and increase economic profit $\left(+3.8 \%,+\$ 9.9 \mathrm{ha}^{-1}\right)$ and irrigation water productivity $\left(+7.2 \%,+0.4 \mathrm{~kg} \mathrm{~m}^{-3}\right)$ while maintaining crop yields. However, the CWSI, ESI, and TSI-based irrigation schemes achieved less crop yields and economic profits than the MAD-based irrigation scheme, especially the CWSI-based irrigation scheme.

The irrigation water use, crop yields, economic profits, and irrigation water productivity of six PWS metrics-based irrigation schemes had spatial variability due to the climate conditions (i.e., aridity index) and soil properties (i.e., sand fraction, the ratio of sand content to the sum of sand, silt, and clay content based on the gSSURGO dataset; Figures 11 and 12 and Table 3). Irrigation water use of the six metrics-based irrigation schemes significantly increased with the aridity index, and slightly increased with the sand fraction (Figures 11a and 11e). Crop yields of the six metrics-based irrigation schemes significantly decreased with the increasing sand fraction, while there was an insignificant trend with the aridity index (Figures 11b and 11f). This indicated that irrigation could compensate for insufficient precipitation in drier regions (such as western Nebraska) while it could not compensate for low water and nutrient holding capacities in sandy soil (Foster et al., 2019). Therefore, high sand fractions at sites-Lowell, East Bayard, and Mitchell led to relatively low crop yields even under high precipitation and/or irrigation (Figure 12b). In addition, economic profits and irrigation water productivity decreased with the increasing aridity index and sand fraction (Figures $11 \mathrm{c}$ and $11 \mathrm{~d}$ and $11 \mathrm{~g}$ and $11 \mathrm{~h}$ ). These results indicated that irrigated agricultural regions with wetter climate and/or lower sand fraction (such as eastern Nebraska) could achieve more economic profits and higher irrigation water productivity than those regions with drier climate and/or higher sand fractions (such as western Nebraska and the Sandhills region in north-central Nebraska).

\section{Discussion}

\subsection{CWP and Stomatal Conductance $\left(G_{S}\right)$ Are the Most Effective Plant-Centric Metrics to Characterize Co-Regulation of Soil Water Supply and Atmospheric Water Demand}

This study is a systematic analysis to understand different PWS metrics, and further confirms the co-regulations of soil water supply and atmospheric water demand on different PWS metrics. The results analysis shows that the co-regulation patterns of different PWS metrics have different sensitivities, while CWP and $G_{\mathrm{S}}$ outperform other three plant-centric PWS metrics with respect to stronger interconnections and relationships to both soil moisture and VPD (Figures 6 and 7). The reason is that CWP and $G_{\mathrm{S}}$ are the most directly responsive metrics to the droughts caused by both soil water deficit (i.e., low soil moisture) and atmospheric dryness (i.e., high VPD). CWP is obtained from the perspective of plant hydraulics, which connects soil, root, stem, leaf, and atmosphere in the SPAC system through the water flow path based on the water potential gradients (Anderegg, 2015). For $G_{S}$, rich plant physiology literature and field experiments have proved that plants tend to close their stomata (i.e., decreased stomatal conductance) to reduce water loss when soil moisture is low and/or VPD is high (Miner \& Bauerle, 2017; Novick et al., 2016).As the results of decreased stomatal conductance, there is a consequent reduction in ET and transpiration, that is,, increased ESI and TSI to indicate PWS (Zhang et al., 2021). With the canopy energy balance, the decreased transpiration results in increased canopy temperature due to less evaporative cooling, that is, increased CWSI to indicate PWS (DeJonge et al., 2015). In general, CWP and $G_{\mathrm{S}}$ are the direct plant physiology responses to water stress, while ESI, TSI, and CWSI are the proxies to approximate PWS.

In addition, the co-regulation of soil moisture and VPD on PWS metrics in Nebraska, part of the United States Corn Belt, has spatial variability. Our relative importance analysis results based on LMG (Figure 9) indicate that for five plant-centric metrics, soil moisture has a larger control in drier regions (such as western Nebraska) where agricultural droughts are dominated by soil water deficit, while VPD has a bigger impact in wetter regions (such as eastern Nebraska). 
(a)

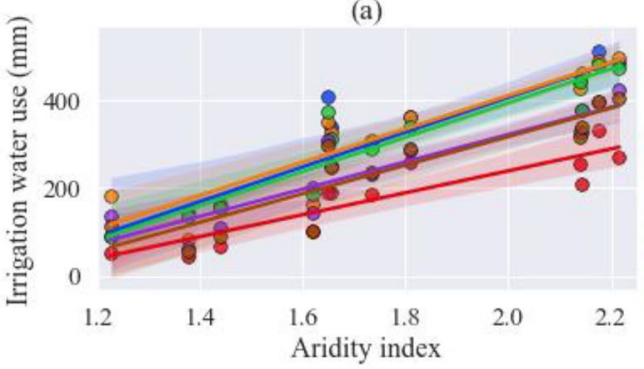

(b)

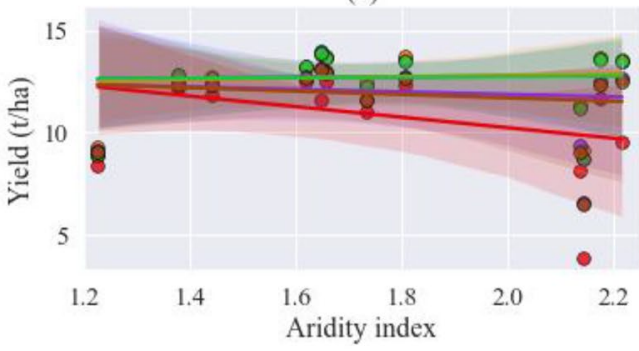

(c)

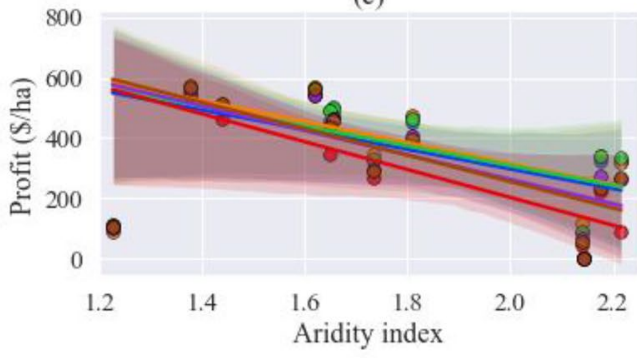

(d)

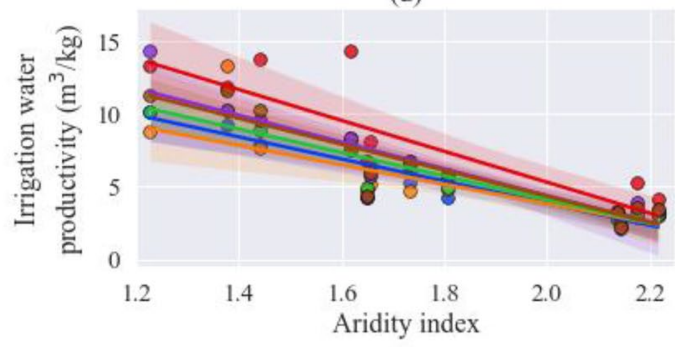

Metrics
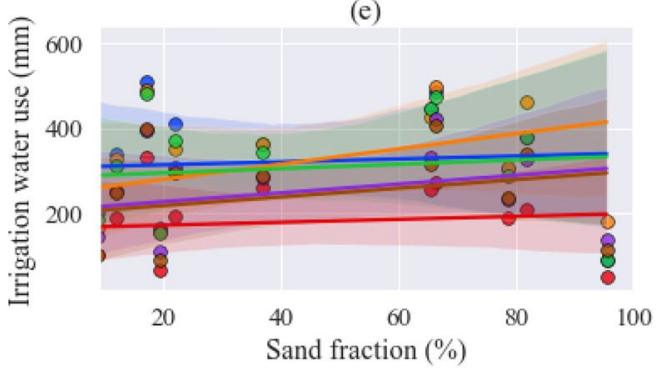

(f)

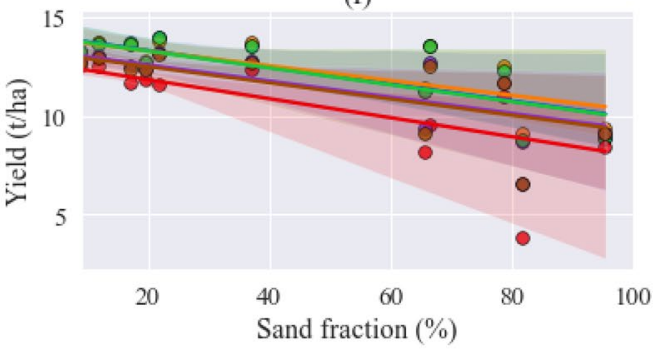

(g)

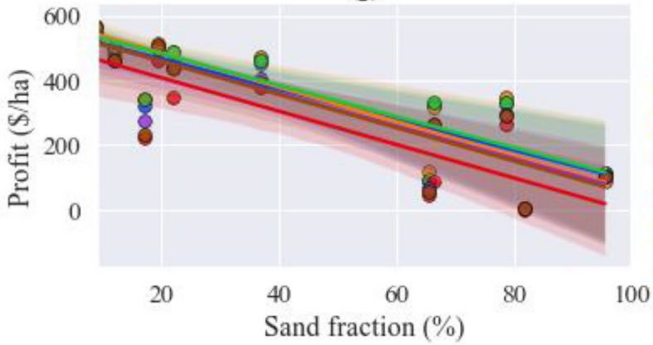

(h)

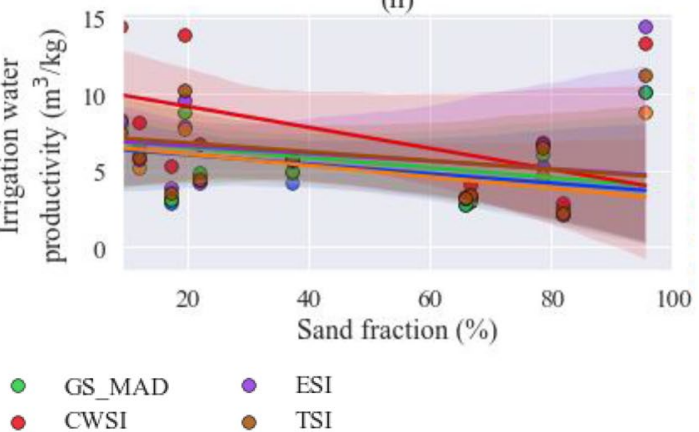

Figure 11. Variation of irrigation water use, yield, profit, and irrigation water productivity with aridity index (a-d) and sand fraction $(\mathrm{e}-\mathrm{h})$ of six PWS metrics-based irrigation schemes with universal thresholds across the 12 sites in Nebraska during 2001-2019. The line denoted the regression line with a 95\% confidence interval.

\subsection{Plant-Centric Irrigation Schemes Could Save Irrigation Water Use}

Our results show that five plant-centric irrigation schemes (CWP, GS_MAD, CWSI, ESI, and TSI) can significantly reduce irrigation water use and thus improve water sustainability, compared to MAD, which only considers soil water supply (Figure 11). Specifically, CWP and GS_MAD-based irrigation schemes can reduce irrigation water use without penalizing maize yields and economic profits, further confirming that CWP and $G_{\mathrm{S}}$ are the most effective PWS metrics with the direct plant physiology responses to water stress. This finding reveals that plants may not have water stress when soil moisture is low and VPD also happens to be low, thus irrigation can be saved without the penalty of crop yields under these conditions. In contrast, although other plant-centric irrigation schemes based on the proxies of PWS (CWSI, ESI, and TSI) also use 


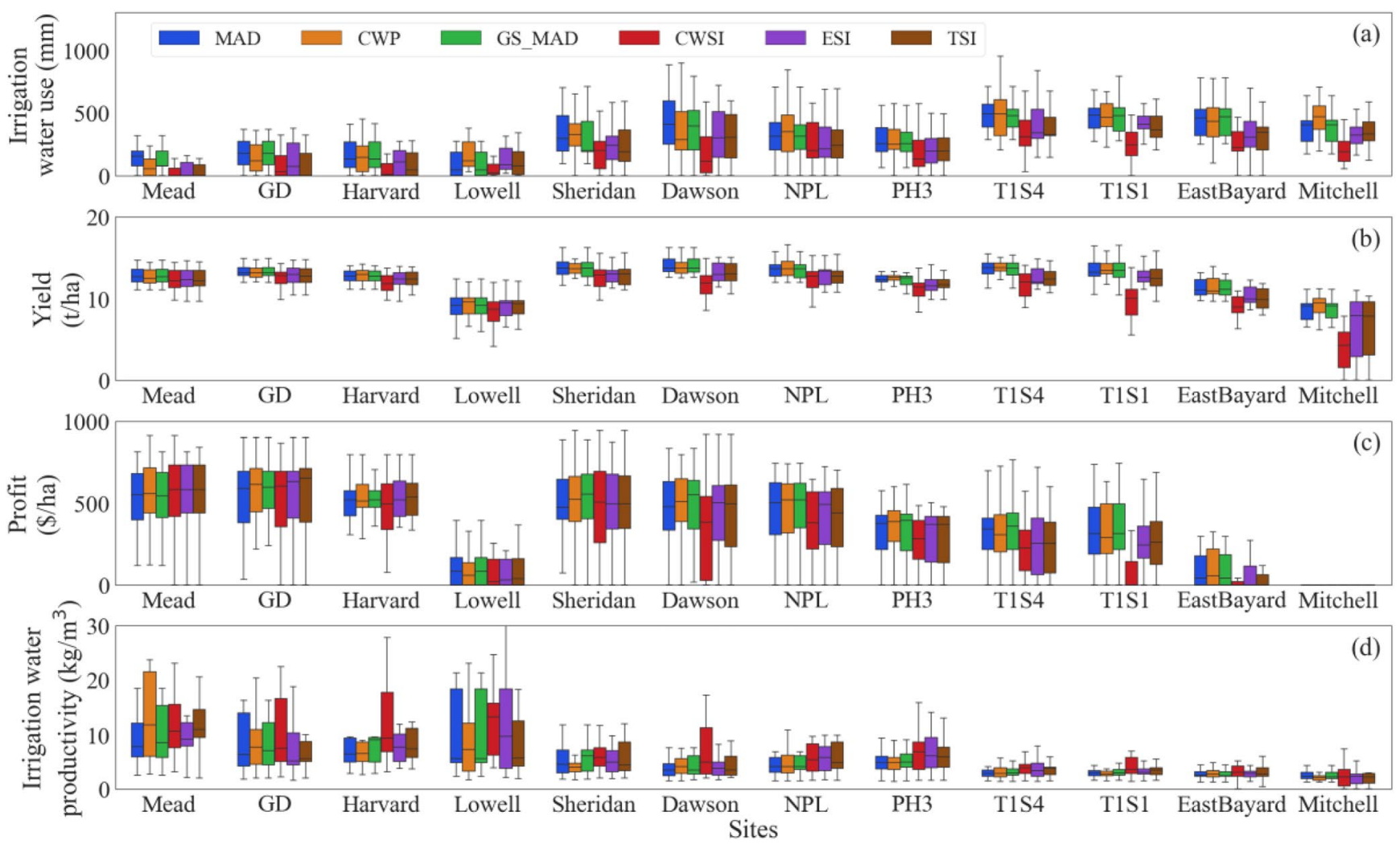

Figure 12. Box plots of (a) irrigation amount, (b) yield, (c) profit, and (d) irrigation water productivity of six PWS metrics-based irrigation schemes with universal thresholds across the 12 sites with a dramatic rainfall gradient in Nebraska (the order of sites from left-Mead to right-Mitchell denotes the decreasing annual rainfall from $900 \mathrm{~mm}$ in the east to $350 \mathrm{~mm}$ in the west) during 2001-2019. Each box represents the 25th and 75th percentiles.

less irrigation water, they do penalize crop yields and reduce the net economic profits. This may reduce the adoption willingness of producers in real applications, even though they could achieve higher irrigation water productivity with larger marginal benefits of irrigation.

It should also be noted that ESI and TSI-based irrigation schemes have higher economic profits than the MAD irrigation scheme in eastern Nebraska at sites-Mead, -GD, and -Harvard, where VPD has non-negligible impacts on PWS. Therefore, five plant-centric irrigation schemes, except CWSI, can achieve higher economic profits with less irrigation water use than the soil-based MAD irrigation scheme in regions where they are equally constrained by both soil water deficit and atmospheric dryness. Currently, the producers' irrigation decision-making in Nebraska mainly focuses on soil water supply (i.e., soil moisture), thus this research encourages producers to consider use of plant-centric irrigation schemes, such as CWP, GS_MAD, ESI, and TSI, to save irrigation water use without penalizing crop yields and economic profits, particularly in eastern Nebraska.

In addition, the CWSI irrigation scheme performs the worst among six irrigation schemes. CWSI, a thermal temperature-driven PWS metric, has been proved that it is spatially effective to differentiate the water stressed and non-stressed plants (Çolak et al., 2015; DeJonge et al., 2015), as canopy temperature is increased under water stress. However, whether that qualifies to be a trigger for irrigation, that is, the effectiveness to indicate the temporal variation of PWS, remains unclear. Our results indicate that the temporal variations of CWSI are not robust to indicate PWS, thus the efficacy of the CWSI irrigation scheme is lower than other irrigation schemes. This means that CWSI is a spatially effective PWS metric, but is ineffective temporally. Thus, the CWSI irrigation scheme is not recommended for irrigation scheduling.

It needs to be noted that the performance of six PWS metric-based irrigation schemes is influenced by their triggering thresholds and the parameters in the irrigation assessment framework, such as the price of maize and irrigation. However, the CWP and GS_MAD irrigation schemes could still achieve the water-saving 
effects, compared to the traditional soil-based MAD irrigation scheme. With the severity of water scarcity, the water-saving effects of the CWP and GS_MAD irrigation schemes will be favored in future.

\subsection{The Practical Implications: How to Incorporate These PWS Metrics Into Practical Irrigation Management?}

Six PWS metrics-based irrigation schemes could be implemented using field measurements and/or satellite observations but accompanied by many challenges. Leaf water potential, soil moisture, and stomatal conductance for CWP, MAD, and GS_MAD irrigation schemes may have to rely on in situ sensors, which usually are labor-intensive and expensive, a situation that may not be changed in the near future. Soil moisture dataset from passive and active microwave satellite-based retrievals has coarse resolutions $(>10 \mathrm{~km}$ in SMAP and SMOS products) and is only sensitive to shallow soil depth $(<0.05 \mathrm{~m})$, thus it is not practically useful for field-scale irrigation (Chan et al., 2016; Zhang et al., 2021). ET, PET (treated as $\mathrm{ET}_{\mathrm{ww}}$ ), canopy temperature, and other meteorological variables, such as air temperature and humidity, could be obtained from satellites and/or nearby weather stations with low costs for ESI and CWSI irrigation schemes (Zhang et al., 2021). It should be noted that the CWSI's upper and lower boundaries of temperature differences, which are crop, growth-stage, and climate specific, need to be estimated using historical measurements (DeJonge et al., 2015; Jackson et al., 1981). For the TSI irrigation scheme, $T_{\mathrm{r}}$ and $T_{\mathrm{r}_{-} w \mathrm{w}}$ could be obtained using the existing ET partitioning approaches but accompanied by large uncertainties (Stoy et al., 2019).

In general, applications of six studied PWS metrics-based irrigation schemes at large-scale require more advanced techniques, and data-model fusion techniques (such as calibration, data assimilation, or physics-guided machine learning) are promising pathways to achieve this goal (Zhang et al., 2021). In particular, to correctly simulating PWS metrics, advanced ecosystem models that resolve mechanisms of plant hydraulics and water-energy-carbon coupling are needed, such as ecosys (Grant, 1995; Zhou et al., 2021), CLM5 (Kennedy et al., 2019), and Noah-MP-PHS (Li et al., 2021). These advanced ecosystem models with above is the prerequisite to enable accurate simulation of PWS metrics, especially how to jointly capture the PWS under soil moisture and VPD stresses (Grant \& Flanagan, 2007; Kennedy et al., 2019; Li et al., 2021; Zhang et al., 2021; Zhou et al., 2021).

To fully implement the data-model fusion for the PWS metric-based irrigation management, we also require reliable and high-fidelity observations that are ideally ubiquitous and cost-effective. Previous satellite products have limited spatial or temporal resolutions, while the recently developed data fusion algorithms and/ or satellites can generate field-scale and high-frequency (e.g., daily) data, such as ET (Anderson et al., 2020; Jiang et al., 2020), LAI (Kimm, Guan, Jiang, et al., 2020), and GPP (Jiang et al., 2021). With the high-quality data, the advanced ecosystem models (such as ecosys used in this study) can be rigorously constrained to reliably simulate both crop dynamics (e.g., stomatal conductance, CWP, ET, and $T_{\mathrm{r}}$ ) and hydrological conditions (e.g., soil moisture; Yang et al., 2020) for different PWS metrics-based irrigation schemes.

\section{Conclusion}

This study interpreted different PWS metrics and assessed their efficacy for guiding irrigation based on the SPAC simulations from a rigorously validated hydraulically driven ecosystem model, ecosys. We found three main points: (a) CWP and stomatal conductance $\left(G_{\mathrm{S}}\right)$ are the most effective plant-centric metrics under the co-regulation of soil water supply (i.e., soil moisture) and atmospheric water demand (i.e., VPD). (b) Five plant-centric metrics-based irrigation schemes could save irrigation water use and increase irrigation water productivity, compared to MAD, the soil-based irrigation scheme. Specifically, CWP and GS_MAD irrigation schemes can reduce irrigation water use and achieve more economic profits without penalizing maize yields, further demonstrating the first key point. (c) The performances of six PWS metrics-based irrigation schemes have spatial variability due to climate and soil properties. The regions with wetter climate and/or lower sand fraction (such as eastern Nebraska) can achieve more economic profits than those regions with drier climate and/or higher sand fraction (such as western Nebraska and the Sandhills). In addition, five plant-centric metrics-based irrigation schemes, except CWSI, perform better than the MAD irrigation scheme in wetter regions (such as eastern Nebraska) where VPD has non-negligible impacts on PWS, suggesting the opportunity of using the plant-centric metrics to improve producers' economic profits through water savings. 


\section{Conflict of Interest}

The authors declare no conflicts of interest relevant to this study.

\section{Data Availability Statement}

This primary data for this research comes from the ecosys model simulations. ecosys can be freely downloaded from GitHub (https://github.com/jinyun1tang/ECOSYS). The field measurements at three AmeriFlux sites (US-Ne1, US-Ne2, and US-Ne3) can be freely accessed from http://fluxnet.fluxdata.org/data/ fluxnet2015-dataset/. The county-level maize yield data can be freely accessed from https:/quickstats.nass. usda.gov/. The model forcing of meteorological variables from the North American Land Data Assimilation System (NLDAS-2) can be freely accessed from https://ldas.gsfc.nasa.gov/nldas/v2/forcing. The model forcing of soil information from the Gridded Soil Survey Geographic Database (gSSURGO) dataset can be freely accessed from https://www.nrcs.usda.gov/wps/portal/nrcs/detail/soils/home/?cid=nrcs142p2_053628.

\section{Acknowledgments}

We acknowledge the support from USDA National Institute of Food and Agriculture Foundational Program Cyber-physical systems (2019-6702129312) and NSF CAREER award (1847334) managed through the NSF Environmental Sustainability Program. We thank all the data providers for this study, including three AmeriFlux sites for the data records, NLDAS- 2 for climate forcing, and gSSURGO for soil information.

\section{References}

Anderegg, W. R. (2015). Spatial and temporal variation in plant hydraulic traits and their relevance for climate change impacts on vegetation. New Phytologist, 205(3), 1008-1014. https://doi.org/10.1111/nph.12907

Anderson, M. C., Gao, F., Knipper, K., Hain, C., Dulaney, W., Baldocchi, D., et al. (2018). Field-scale assessment of land and water use change over the California Delta using remote sensing. Remote Sensing, 10(6), 889. https://doi.org/10.3390/rs10060889

Anderson, M. C., Hain, C., Wardlow, B., Pimstein, A., Mecikalski, J. R., \& Kustas, W. P. (2011). Evaluation of drought indices based on thermal remote sensing of evapotranspiration over the continental United States. Journal of Climate, 24(8), 2025-2044. https://doi. org/10.1175/2010jcli3812.1

Anderson, M. C., Norman, J. M., Mecikalski, J. R., Otkin, J. A., \& Kustas, W. P. (2007). A climatological study of evapotranspiration and moisture stress across the continental United States based on thermal remote sensing: 1. Model formulation. Journal of Geophysical Research, 112(D10), D10117. https://doi.org/10.1029/2006jd007506

Anderson, M. C., Yang, Y., Xue, J., Knipper, K. R., Yang, Y., Gao, F., et al. (2020). Interoperability of ECOSTRESS and Landsat for mapping evapotranspiration time series at sub-field scales. Remote Sensing of Environment, 252, 112189. https://doi.org/10.1016/j.rse.2020.112189

Anderson, M. C., Zolin, C. A., Sentelhas, P. C., Hain, C. R., Semmens, K., Tugrul Yilmaz, M., et al. (2016). The Evaporative Stress Index as an indicator of agricultural drought in Brazil: An assessment based on crop yield impacts. Remote Sensing of Environment, 174, 82-99. https://doi.org/10.1016/j.rse.2015.11.034

Ball, J. T., Woodrow, I. E., \& Berry, J. A. (1987). A model predicting stomatal conductance and its contribution to the control of photosynthesis under different environmental conditions. In J. Biggins (Ed.), Progress in photosynthesis research (pp. 221-224). Springer. https:// doi.org/10.1007/978-94-017-0519-6_48

Bordonaba, J. G., \& Terry, L. A. (2010). Manipulating the taste-related composition of strawberry fruits (Fragaria $\times$ ananassa) from different cultivars using deficit irrigation. Food Chemistry, 122(4), 1020-1026. https://doi.org/10.1016/j.foodchem.2010.03.060

Buckley, T. N. (2017). Modeling stomatal conductance. Plant Physiology, 174(2), 572-582. https://doi.org/10.1104/pp.16.01772

Buckley, T. N., \& Mott, K. A. (2013). Modelling stomatal conductance in response to environmental factors. Plant, Cell and Environment, 36(9), 1691-1699. https://doi.org/10.1111/pce.12140

Carbonell-Barrachina, Á. A., Memmi, H., Noguera-Artiaga, L., Gijón-López, M. d. C., Ciapa, R., \& Pérez-López, D. (2015). Quality attributes of pistachio nuts as affected by rootstock and deficit irrigation. Journal of the Science of Food and Agriculture, 95(14), 2866-2873. https://doi.org/10.1002/jsfa.7027

Chan, S. K., Bindlish, R., O'Neill, P. E., Njoku, E., Jackson, T., Colliander, A., et al. (2016). Assessment of the SMAP passive soil moisture product. IEEE Transactions on Geoscience and Remote Sensing, 54(8), 4994-5007. https://doi.org/10.1109/tgrs.2016.2561938

Cohen, Y., Alchanatis, V., Meron, M., Saranga, Y., \& Tsipris, J. (2005). Estimation of leaf water potential by thermal imagery and spatial analysis*. Journal of Experimental Botany, 56(417), 1843-1852. https://doi.org/10.1093/jxb/eri174

Çolak, Y. B., Yazar, A., Çolak, İ., Akça, H., \& Duraktekin, G. (2015). Evaluation of Crop Water Stress Index (CWSI) for eggplant under varying irrigation regimes using surface and subsurface drip systems. Agriculture and Agricultural Science Procedia, 4, 372-382. https:// doi.org/10.1016/j.aaspro.2015.03.042

DeJonge, K. C., Taghvaeian, S., Trout, T. J., \& Comas, L. H. (2015). Comparison of canopy temperature-based water stress indices for maize. Agricultural Water Management, 156, 51-62. https://doi.org/10.1016/j.agwat.2015.03.023

Dimitrov, D. D., Grant, R. F., Lafleur, P. M., \& Humphreys, E. R. (2011). Modeling the effects of hydrology on gross primary productivity and net ecosystem productivity at Mer Bleue bog. Journal of Geophysical Research: Biogeosciences, 116(G4), G04010. https://doi. org/10.1029/2010jg001586

Dukes, M. D., Zotarelli, L., \& Morgan, K. T. (2010). Use of irrigation technologies for vegetable crops in Florida. HortTechnology, 20(1), 133-142. https://doi.org/10.21273/horttech.20.1.133

Enquist, B. J., Kerkhoff, A. J., Huxman, T. E., \& Economo, E. P. (2007). Adaptive differences in plant physiology and ecosystem paradoxes: Insights from metabolic scaling theory. Global Change Biology, 13(3), 591-609. https://doi.org/10.1111/j.1365-2486.2006.01222.x

Fernández, J. E., Alcon, F., Diaz-Espejo, A., Hernandez-Santana, V., \& Cuevas, M. V. (2020). Water use indicators and economic analysis for on-farm irrigation decision: A case study of a super high density olive tree orchard. Agricultural Water Management, 237, 106074. https://doi.org/10.1016/j.agwat.2020.106074

Foster, T., Gonçalves, I. Z., Campos, I., Neale, C. M. U., \& Brozović, N. (2019). Assessing landscape scale heterogeneity in irrigation water use with remote sensing and in situ monitoring. Environmental Research Letters, 14(2), 024004. https://doi.org/10.1088/1748-9326/ aaf2be 
Gibson, J., Franz, T. E., Wang, T., Gates, J., Grassini, P., Yang, H., \& Eisenhauer, D. (2017). A case study of field-scale maize irrigation patterns in western Nebraska: Implications for water managers and recommendations for hyper-resolution land surface modeling. Hydrology and Earth System Sciences, 21(2), 1051-1062. https://doi.org/10.5194/hess-21-1051-2017

González-Dugo, M. P., Chen, X., Andreu, A., Carpintero, E., Gómez-Giraldez, P. J., Carrara, A., \& Su, Z. (2021). Long-term water stress and drought assessment of Mediterranean oak savanna vegetation using thermal remote sensing. Hydrology and Earth System Sciences, 25(2), 755-768. https://doi.org/10.5194/hess-25-755-2021

Grant, R. F. (1995). Salinity, water use and yield of maize: Testing of the mathematical model ecosys. Plant and Soil, 172(2), 309-322. https://doi.org/10.1007/bf00011333

Grant, R. F. (1997). Changes in soil organic matter under different tillage and rotation: Mathematical modeling in ecosys. Soil Science Society of America Journal, 61(4), 1159-1175. https://doi.org/10.2136/sssaj1997.03615995006100040023x

Grant, R. F. (2001). A review of the Canadian ecosystem model ecosys. In: Modeling carbon and nitrogen dynamics for soil management (pp. 173-264). CRC Press

Grant, R. F., Arkebauer, T. J., Dobermann, A., Hubbard, K. G., Schimelfenig, T. T., Suyker, A. E., et al. (2007). Net biome productivity of irrigated and rainfed maize-soybean rotations: Modeling vs. measurements. Agronomy Journal, 99(6), 1404-1423. https://doi.org/10.2134/ agronj2006.0308

Grant, R. F., Dyck, M., \& Puurveen, D. (2020). Nitrogen and phosphorus control carbon sequestration in agricultural ecosystems: Modelling carbon, nitrogen, and phosphorus balances at the Breton Plots with ecosys under historical and future climates. Canadian Journal of Soil Science, 100(4), 408-429. https://doi.org/10.1139/cjss-2019-0132

Grant, R. F., \& Flanagan, L. B. (2007). Modeling stomatal and nonstomatal effects of water deficits on CO2 fixation in a semiarid grassland. Journal of Geophysical Research: Biogeosciences, 112(G3), G03011. https://doi.org/10.1029/2006jg000302

Grant, R. F., Jarvis, P. G., Massheder, J. M., Hale, S. E., Moncrieff, J. B., Rayment, M., et al. (2001). Controls on carbon and energy exchange by a black spruce-moss ecosystem: Testing the mathematical model ecosys with data from the BOREAS Experiment. Global Biogeochemical Cycles, 15(1), 129-147. https://doi.org/10.1029/2000gb001306

Grant, R. F., Juma, N., Robertson, J., Izaurralde, R., \& McGill, W. B. (2001). Long-term changes in soil carbon under different fertilizer, manure, and rotation: Testing the mathematical model ecosys with data from the Breton plots. Soil Science Society of America Journal, 65(1), 205-214. https://doi.org/10.2136/sssaj2001.651205x

Grant, R. F., Kimball, B. A., Conley, M., White, J., Wall, G., \& Ottman, M. J. (2011). Controlled warming effects on wheat growth and yield: Field measurements and modeling. Agronomy Journal, 103(6), 1742-1754. https://doi.org/10.2134/agronj2011.0158

Grant, R. F., Kimball, B. A., Wall, G. W., Triggs, J. M., Brooks, T. J., Pinter, P. J., et al. (2004). Modeling elevated carbon dioxide effects on water relations, water use, and growth of irrigated sorghum. Agronomy Journal, 96(6), 1693-1705. https://doi.org/10.2134/agronj2004.1693

Grant, R. F., Lin, S., \& Hernandez-Ramirez, G. (2020b). Modelling nitrification inhibitor effects on N2O emissions after fall-and spring-applied slurry by reducing nitrifier NH4+ oxidation rate. Biogeosciences, 17(7), 2021-2039. https://doi.org/10.5194/bg-17-2021-2020

Grant, R. F., Rochette, P., \& Desjardins, R. (1993). Energy exchange and water use efficiency of field crops: Validation of a simulation model. Agronomy Journal, 85(4), 916-928. https://doi.org/10.2134/agronj1993.00021962008500040025x

Grant, R. F., Wall, G., Kimball, B., Frumau, K., Pinter, P., Jr., Hunsaker, D., \& Lamorte, R. (1999). Crop water relations under different CO2 and irrigation: Testing of ecosys with the free air CO2 enrichment (FACE) experiment. Agricultural and Forest Meteorology, 95(1), 27-51. https://doi.org/10.1016/s0168-1923(99)00017-9

Grömping, U. (2006). Relative importance for linear regression in R: The package relaimpo. Journal of Statistical Software, 17(1), 1-27. https://doi.org/10.18637/jss.v017.i01

Grömping, U. (2007). Estimators of relative importance in linear regression based on variance decomposition. The American Statistician, 61(2), 139-147. https://doi.org/10.1198/000313007x188252

Grossiord, C., Buckley, T. N., Cernusak, L. A., Novick, K. A., Poulter, B., Siegwolf, R. T., et al. (2020). Plant responses to rising vapor pressure deficit. New Phytologist, 226(6), 1550-1566. https://doi.org/10.1111/nph.16485

Herve, C. (2014). The basics of plant hydraulics. Journal of Plant Hydraulics, 1, e001.

Hoffmann, H., Jensen, R., Thomsen, A., Nieto, H., Rasmussen, J., \& Friborg, T. (2016). Crop water stress maps for an entire growing season from visible and thermal UAV imagery. Biogeosciences, 13(24), 6545-6563. https://doi.org/10.5194/bg-13-6545-2016

Idso, S. B., Jackson, R., Pinter, P., Jr., Reginato, R., \& Hatfield, J. (1981). Normalizing the stress-degree-day parameter for environmental variability. Agricultural Meteorology, 24, 45-55. https://doi.org/10.1016/0002-1571(81)90032-7

Idso, S. B., Reginato, R. J., \& Farah, S. M. (1982). Soil- and atmosphere-induced plant water stress in cotton as inferred from foliage temperatures. Water Resources Research, 18(4), 1143-1148. https://doi.org/10.1029/wr018i004p01143

Ihuoma, S. O., \& Madramootoo, C. A. (2017). Recent advances in crop water stress detection. Computers and Electronics in Agriculture, 141, 267-275. https://doi.org/10.1016/j.compag.2017.07.026

Jackson, R. D., Idso, S., Reginato, R., \& Pinter, P., Jr. (1981). Canopy temperature as a crop water stress indicator. Water Resources Research, 17(4), 1133-1138. https://doi.org/10.1029/wr017i004p01133

Jackson, R. D., Kustas, W. P., \& Choudhury, B. J. (1988). A reexamination of the crop water stress index. Irrigation Science, 9(4), 309-317. https://doi.org/10.1007/bf00296705

Jiang, C., Guan, K., Pan, M., Ryu, Y., Peng, B., \& Wang, S. (2020). BESS-STAIR: A framework to estimate daily, 30 m, and all-weather crop evapotranspiration using multi-source satellite data for the US Corn Belt, Hydrology and Earth System Sciences, 24(3), 1251-1273. https://doi.org/10.5194/hess-24-1251-2020

Jiang, C., Guan, K., Wu, G., Peng, B., \& Wang, S. (2021). A daily, $250 \mathrm{~m}$ and real-time gross primary productivity product (2000-present) covering the contiguous United States. Earth System Science Data, 13(2), 281-298. https://doi.org/10.5194/essd-13-281-2021

Jones, H. G. (1990). Plant water relations and implications for irrigation scheduling. Leuven, Belgium: International Society for Horticultural Science (ISHS).

Kennedy, D., Swenson, S., Oleson, K. W., Lawrence, D. M., Fisher, R., Lola da Costa, A. C., \& Gentine, P. (2019). Implementing plant hydraulics in the community land model, Version 5. Journal of Advances in Modeling Earth Systems, 11(2), 485-513. https://doi. org/10.1029/2018ms001500

Kimm, H., Guan, K., Gentine, P., Wu, J., Bernacchi, C. J., Sulman, B. N., et al. (2020). Redefining droughts for the U.S. Corn Belt: The dominant role of atmospheric vapor pressure deficit over soil moisture in regulating stomatal behavior of Maize and Soybean. Agricultural and Forest Meteorology, 287, 107930. https://doi.org/10.1016/j.agrformet.2020.107930

Kimm, H., Guan, K., Jiang, C., Peng, B., Gentry, L. F., Wilkin, S. C., et al. (2020). Deriving high-spatiotemporal-resolution leaf area index for agroecosystems in the U.S. Corn Belt using Planet Labs CubeSat and STAIR fusion data. Remote Sensing of Environment, 239,111615 https://doi.org/10.1016/j.rse.2019.111615 
Kirnak, H., Irik, H. A., \& Unlukara, A. (2019). Potential use of crop water stress index (CWSI) in irrigation scheduling of drip-irrigated seed pumpkin plants with different irrigation levels. Scientia Horticulturae, 256, 108608. https://doi.org/10.1016/j.scienta.2019.108608

Kullberg, E. G., DeJonge, K. C., \& Chávez, J. L. (2017). Evaluation of thermal remote sensing indices to estimate crop evapotranspiration coefficients. Agricultural Water Management, 179, 64-73. https://doi.org/10.1016/j.agwat.2016.07.007

Kumar, A., Nayak, A., Pani, D., \& Das, B. (2017). Physiological and morphological responses of four different rice cultivars to soil water potential based deficit irrigation management strategies. Field Crops Research, 205, 78-94. https://doi.org/10.1016/j.fcr.2017.01.026

Lehmann, N., Finger, R., Klein, T., Calanca, P., \& Walter, A. (2013). Adapting crop management practices to climate change: Modeling optimal solutions at the field scale. Agricultural Systems, 117, 55-65. https://doi.org/10.1016/j.agsy.2012.12.011

Leinonen, I., Grant, O., Tagliavia, C., Chaves, M., \& Jones, H. (2006). Estimating stomatal conductance with thermal imagery. Plant, Cell and Environment, 29(8), 1508-1518. https://doi.org/10.1111/j.1365-3040.2006.01528.x

Li, L., Yang, Z.-L., Matheny, A. M., Zheng, H., Swenson, S. C., Lawrence, D. M., et al. (2021). Representation of plant hydraulics in the Noah-MP land surface model: Model development and multiscale evaluation. Journal of Advances in Modeling Earth Systems, 13(4), e2020MS002214. https://doi.org/10.1029/2020ms002214

Lin, C., Gentine, P., Huang, Y., Guan, K., Kimm, H., \& Zhou, S. (2018). Diel ecosystem conductance response to vapor pressure deficit is suboptimal and independent of soil moisture. Agricultural and Forest Meteorology, 250-251, 24-34. https://doi.org/10.1016/j. agrformet.2017.12.078

Liu, L., Gudmundsson, L., Hauser, M., Qin, D., Li, S., \& Seneviratne, S. I. (2020). Soil moisture dominates dryness stress on ecosystem production globally. Nature Communications, 11(1), 4892. https://doi.org/10.1038/s41467-020-18631-1

Lobell, D. B., Roberts, M. J., Schlenker, W., Braun, N., Little, B. B., Rejesus, R. M., \& Hammer, G. L. (2014). Greater sensitivity to drought accompanies maize yield increase in the US Midwest. Science, 344(6183), 516-519. https://doi.org/10.1126/science.1251423

López, J., Way, D. A., \& Sadok, W. (2021). Systemic effects of rising atmospheric vapor pressure deficit on plant physiology and productivity. Global Change Biology, 27(9), 1704-1720. https://doi.org/10.1111/gcb.15548

Malejane, D. N., Tinyani, P., Soundy, P., Sultanbawa, Y., \& Sivakumar, D. (2018). Deficit irrigation improves phenolic content and antioxidant activity in leafy lettuce varieties. Food Science \& Nutrition, 6(2), 334-341. https://doi.org/10.1002/fsn3.559

Massmann, A., Gentine, P., \& Lin, C. (2019). When does vapor pressure deficit drive or reduce evapotranspiration? Journal of Advances in Modeling Earth Systems, 11(10), 3305-3320. https://doi.org/10.1029/2019ms001790

Medlyn, B. E., Duursma, R. A., Eamus, D., Ellsworth, D. S., Prentice, I. C., Barton, C. V., et al. (2011). Reconciling the optimal and empirical approaches to modelling stomatal conductance. Global Change Biology, 17(6), 2134-2144. https://doi.org/10.1111/j.1365-2486.2010.02375.x

Miner, G. L., \& Bauerle, W. L. (2017). Seasonal variability of the parameters of the Ball-Berry model of stomatal conductance in maize (Zea mays L.) and sunflower (Helianthus annuus L.) under well-watered and water-stressed conditions. Plant, Cell and Environment, 40(9), 1874-1886. https://doi.org/10.1111/pce.12990

Moriana, A., Pérez-López, D., Prieto, M. H., Ramírez-Santa-Pau, M., \& Pérez-Rodriguez, J. M. (2012). Midday stem water potential as a useful tool for estimating irrigation requirements in olive trees. Agricultural Water Management, 112, 43-54. https://doi.org/10.1016/j. agwat.2012.06.003

Najafi, E., Devineni, N., Khanbilvardi, R. M., \& Kogan, F. (2018). Understanding the changes in global crop yields through changes in climate and technology. Earth's Future, 6(3), 410-427. https://doi.org/10.1002/2017ef000690

Nandan, R., Woo, D. K., Kumar, P., \& Adinarayana, J. (2021). Impact of irrigation scheduling methods on corn yield under climate change. Agricultural Water Management, 255, 106990. https://doi.org/10.1016/j.agwat.2021.106990

Novick, K. A., Ficklin, D. L., Stoy, P. C., Williams, C. A., Bohrer, G., Oishi, A. C., et al. (2016). The increasing importance of atmospheric demand for ecosystem water and carbon fluxes. Nature Climate Change, 6(11), 1023-1027. https://doi.org/10.1038/nclimate3114

NRCS (2010). Soil survey staff, natural resources conservation service. United States department of agriculture, Soil Survey Geographic (SSURGO) Database for northeast Tennessee.

Osakabe, Y., Osakabe, K., Shinozaki, K., \& Tran, L.-S. (2014). Response of plants to water stress. Frontiers of Plant Science, 5(86). https:// doi.org/10.3389/fpls.2014.00086

Panda, R., Behera, S., \& Kashyap, P. (2004). Effective management of irrigation water for maize under stressed conditions. Agricultural Water Management, 66(3), 181-203. https://doi.org/10.1016/j.agwat.2003.12.001

Passioura, J. B. (1982). Water in the Soil-Plant-Atmosphere Continuum. In O. L. Lange, P. S. Nobel, C. B. Osmond, \& H. Ziegler (Eds.), Physiological plant ecology II: Water relations and carbon assimilation (pp. 5-33). Berlin, Heidelberg: Springer. https://doi. org/10.1007/978-3-642-68150-9_2

Peng, B., Guan, K., Chen, M., Lawrence, D. M., Pokhrel, Y., Suyker, A., et al. (2018). Improving maize growth processes in the community land model: Implementation and evaluation. Agricultural and Forest Meteorology, 250, 64-89. https://doi.org/10.1016/j. agrformet.2017.11.012

Philip, J. R. (1966). Plant water relations: Some physical aspects. Annual Review of Plant Physiology, 17(1), 245-268. https://doi.org/10.1146/ annurev.pp.17.060166.001333

Porporato, A., Laio, F., Ridolfi, L., \& Rodriguez-Iturbe, I. (2001). Plants in water-controlled ecosystems: Active role in hydrologic processes and response to water stress: III. Vegetation water stress. Advances in Water Resources, 24(7), 725-744. https://doi.org/10.1016/ s0309-1708(01)00006-9

Saseendran, S. A., Ahuja, L. R., Nielsen, D. C., Trout, T. J., \& Ma, L. (2008). Use of crop simulation models to evaluate limited irrigation management options for corn in a semiarid environment. Water Resources Research, 44(7), W00E02. https://doi.org/10.1029/2007wr006181

Sezen, S. M., Yazar, A., Daşgan, Y., Yucel, S., Akyıldız, A., Tekin, S., \& Akhoundnejad, Y. (2014). Evaluation of crop water stress index (CWSI) for red pepper with drip and furrow irrigation under varying irrigation regimes. Agricultural Water Management, 143, 59-70. https://doi.org/10.1016/j.agwat.2014.06.008

Sinclair, T. R. (2012). Is transpiration efficiency a viable plant trait in breeding for crop improvement? Functional Plant Biology, 39(5), 359-365. https://doi.org/10.1071/fp11198

Sinclair, T. R. (2018). Effective water use required for improving crop growth rather than transpiration efficiency. Frontiers of Plant Science, 9, 1442. https://doi.org/10.3389/fpls.2018.01442

Sinclair, T. R., Tanner, C., \& Bennett, J. (1984). Water-use efficiency in crop production. BioScience, 34(1), 36-40. https://doi. org/10.2307/1309424

Smart, R., \& Barrs, H. (1973). The effect of environment and irrigation interval on leaf water potential of four horticultural species. Agricultural Meteorology, 12, 337-346. https://doi.org/10.1016/0002-1571(73)90030-7 
Stoy, P. C., El-Madany, T., Fisher, J. B., Gentine, P., Gerken, T., Good, S. P., et al. (2019). Reviews and syntheses: Turning the challenges of partitioning ecosystem evaporation and transpiration into opportunities. Biogeosciences Discussions, 16, 3747-3775. https://doi. org/10.5194/bg-16-3747-2019

USDA, N. A. S. S (2017). 2017 census of agriculture. United States Department of Agriculture.

Van Bavel, C., \& Hillel, D. (1976). Calculating potential and actual evaporation from a bare soil surface by simulation of concurrent flow of water and heat. Agricultural Meteorology, 17(6), 453-476. https://doi.org/10.1016/0002-1571(76)90022-4

Yang, J., Duursma, R. A., De Kauwe, M. G., Kumarathunge, D., Jiang, M., Gimeno, KMTE., et al. (2019). Incorporating non-stomatal limitation improves the performance of leaf and canopy models at high vapour pressure deficit. Tree Physiology, 39(12), 1961-1974. https:// doi.org/10.1093/treephys/tpz103

Yang, Y., Guan, K., Peng, B., Pan, M., Jiang, C., \& Franz, T. E. (2020). High-resolution spatially explicit land surface model calibration using field-scale satellite-based daily evapotranspiration product. Journal of Hydrology, 596, 125730. https://doi.org/10.1016/j. jhydrol.2020.125730

Zhang, J., Guan, K., Peng, B., Jiang, C., Zhou, W., Yang, Y., et al. (2021). Challenges and opportunities in precision irrigation decision-support systems for center pivots. Environmental Research Letters, 16(5), 053003. https://doi.org/10.1088/1748-9326/abe436

Zhou, W., Guan, K., Peng, B., Shi, J., Jiang, C., Wardlow, B., et al. (2020). Connections between the hydrological cycle and crop yield in the rainfed US Corn Belt. Journal of Hydrology, 590, 125398. https://doi.org/10.1016/j.jhydrol.2020.125398

Zhou, W., Guan, K., Peng, B., Tang, J., Jin, Z., Jiang, C., et al. (2021). Quantifying carbon budget, crop yields and their responses to environmental variability using the ecosys model for U.S. Midwestern agroecosystems. Agricultural and Forest Meteorology, 307, 108521. https:// doi.org/10.1016/j.agrformet.2021.10852 